\title{
Biomimetic Superlyophobic Metallic Surfaces: Focusing on Their Fabrication and Applications
}

\author{
Zhongxu Lian ${ }^{1}$, Jinkai Xu ${ }^{1^{*}}$, Zuobin Wang ${ }^{1,2}$, Huadong $\mathbf{Y u}^{1^{*}}$ \\ 1. Ministry of Education Key Laboratory for Cross-Scale Micro and Nano Manufacturing, Changchun University of Science and \\ Technology, Changchun 130022, China \\ 2. International Research Centre for Nano Handling and Manufacturing of China, Changchun University of Science and Technology,
} Changchun 130022, China

\begin{abstract}
Metals are indispensable engineered materials for day-to-day life. Researches focused on metallic surfaces with superlyophobicity (superhydrophobicity, superoleophobicity, underwater superoleophobicity and slippery characteristic) have attracted much attention recently. Nature is a magician that gives each organic life a unique advantage. Researchers have created a large number of biomimetic superlyophobic metallic surfaces through various approaches. These biomimetic superlyophobic metallic surfaces exhibit advantages in many applications, such as self-cleaning, corrosion resistance, anti-icing, and drag reduction. In this review, the specific fabrication and applications of biomimetic superlyophobic metallic surfaces were reported. The remaining challenges and future outlook of biomimetic superlyophobic metallic surfaces were preliminarily analyzed. It is hoped that the review will be essential for broadening the scope of potential applications of metals and providing a powerful reference for future research on metal-based advanced functional materials.
\end{abstract}

Keywords: biomimetic, metallic surfaces, superhydrophobicity, superoleophobicity, underwater superoleophobicity, slippery characteristic Copyright $(C)$ The author(s) 2020 .

\section{Introduction}

The existing organisms in nature need to continuously optimize themselves on the macro or micro scale to survive and develop, and the optimization methods are worthy of our reference. Previous studies have found that surface microstructures of organisms lead to the formation of many special functions. Cockroaches are able to move freely through soil because of the presence of depressions and bristle structures on the surfaces $^{[1]}$. Butterflies have colorful wings due to the existence of the pit-like multilayer film on the surfaces that cause interference of light waves ${ }^{[2]}$. Pangolins have high wear resistance resulting from their prismatic and laminated structures ${ }^{[3]}$. Dragonfly wings and tree leaves show anti-fatigue property because the surface of dragonfly wings has tubular-like asymmetric hollow structures and the surface of leaves has irregular vein structures $^{[4,5]}$. The functional and structural characteristics of these organisms and solutions to their application in engineering technologies have become a hot topic in the field of biomimetic science research.

\footnotetext{
*Corresponding author: Jinkai Xu, Huadong Yu

E-mail: xujinkai2000@163.com, yuhuadong@cust.edu.cn
}

Researchers have found that organisms such as lotus leaves have special wettability resulting from the microstructure on their surface ${ }^{[6,7]}$. As typical special wettability materials, superhydrophobic, superoleophobic, underwater superoleophobic and slippery liquidinfused porous surfaces (collectively referred to as superlyophobic surfaces) are the most widely studied interfaces because of their excellent water- or oil-repellent ability in air or water ${ }^{[8-21]}$. Up to now, various superlyophobic surfaces have been reported and widely employed in many different fields, such as self-cleaning ${ }^{[22-30]}$, anti-fouling ${ }^{[31-40]}$, anti-fogging ${ }^{[41-47]}$, anti-icing $^{[48-54]}$, corrosion resistance ${ }^{[55-62]}$, drag reduction $^{[63-70]}$, microfluidics ${ }^{[71-78]}$, lab-on-a-chip ${ }^{[79-83]}$, cell engineering ${ }^{[84-90]}$, micro-droplet manipulation ${ }^{[91-102]}$, oil/water separation ${ }^{[103-116]}$, guiding liquid sliding ${ }^{[117-123]}$, water collection ${ }^{[124-128]}$, surface-enhanced Raman scattering ${ }^{[129-131]}$ and super-buoyant micro-boats ${ }^{[132-136]}$.

Metals, widely used in construction, shipbuilding, bridges, electric power and other industries, are indispensable engineered materials in our society ${ }^{[137]}$. On the other hand, problems such as corrosion and icing tend to 
occur while using metallic materials, resulting in poor performance of metallic equipment and even serious safety hazards. Superlyophobic surfaces can effectively delay corrosion and icing due to their water-repellent capacity, so the fabrication of superlyophobic metallic surfaces is of great significance in improving the properties of materials and expanding the application range of materials ${ }^{[138]}$. The article is composed of five sections to review the recent progress of biomimetic superlyophobic metallic surfaces. The superlyophobic phenomenon in nature was briefly summarized in section 2 . Section $\mathbf{3}$ is modeling and design. Sections $\mathbf{4}$ and $\mathbf{5}$ described the preparation and applications of biomimetic superlyophobic metallic surfaces. In the end, challenges and future trends of biomimetic superlyophobic metallic surfaces were preliminarily discussed.

\section{Superlyophobic phenomenon in nature}

After billions of years of natural evolution, the animals and plants have evolved almost perfect microstructures which show charming functions. Taking wettability as an example, many typical functional natural materials have been reported (Table 1). The special surface functions of these materials can be observed from the table. These findings will provide us unique strategies for future research on advanced functional materials with special wettability. The following are some of the common surfaces of animals and plants with special wetting properties in nature.

\subsection{Lotus leaf}

In nature, lotus leaf is one of the typical superhydrophobic surfaces, as shown in Fig. 1a, representing a water contact angle greater than $150^{\circ}$. Furthermore, it also shows an ultra-low adhesion of water, resulting in a fascinating self-cleaning capacity (Figs. $1 \mathrm{~b}$ and $1 \mathrm{c}$ ). In 1997, Neinhuis et al. ${ }^{[7]}$ first observed and studied the microstructure of the lotus leaf surface by means of Scanning Electron Microscopy (SEM). The surface of the lotus leaf was not smooth, and micron-sized mastoid structures and the hydrophobic waxy layer were observed. In further research work, Barthlott et al. ${ }^{[166-168]}$ found micron-sized mastoid structures and nanoscale structures randomly distributed on the lotus leaf surface, as shown in Figs. 1d-1f. When water fell on lotus leaves, microstructures greatly reduced the actual contact area between the droplet and the lotus surface.

\subsection{Springtail}

Werner et al. ${ }^{[160,169-172]}$ reported the most typical examples of superoleophobicity in natural species, and investigated micro-nanoscale structures of different species of springtails (Fig. 2). The surface of springtails has highly ordered structures which make them possible to survive in the environment. These structures make the springtail skin superoleophobic and resistant to wetting

Table 1 Typical natural materials with special wettability and properties

\begin{tabular}{cccc}
\hline Natural materials & Functions & Refs. \\
\hline Lotus leaf & Superhydrophobicity, self-cleaning, low adhesion & {$[139-141]$} \\
Salvinia & Superhydrophobicity, air-retention & {$[142]$} \\
Rice leaf & Superhydrophobicity, anisotropic wetting, low drag & {$[143,144]$} \\
Rose petal & Superhydrophobicity, structural color, high adhesion & {$[145,146]$} \\
Butterfly wing & Superhydrophobicity, structural color, antireflection, directional adhesion, antifogging & {$[2,147-150]$} \\
Cicada wing & Superhydrophobicity, antireflection & {$[151,152]$} \\
Gecko foot & Superhydrophobicity, high adhesive, reversible adhesive & {$[153-155]$} \\
Water strider leg & Superhydrophobicity, water-repellent, antifogging & {$[156,157]$} \\
Mosquito compound eye & Superhydrophobicity, antifogging & Superoleophobicity \\
Springtail & Superoleophobicity, self-cleaning & {$[158]$} \\
Snail shell & Underwater superoleophobicity & {$[160]$} \\
Fish scale & Underwater superoleophobicity, directional adhesion & {$[163]$} \\
Striped fish & Underwater superoleophobicity, mechanical property, strength, toughness \\
Nacre & Underwater superoleophobicity, low drag, antifouling & {$[164]$} \\
Shark skin & &
\end{tabular}



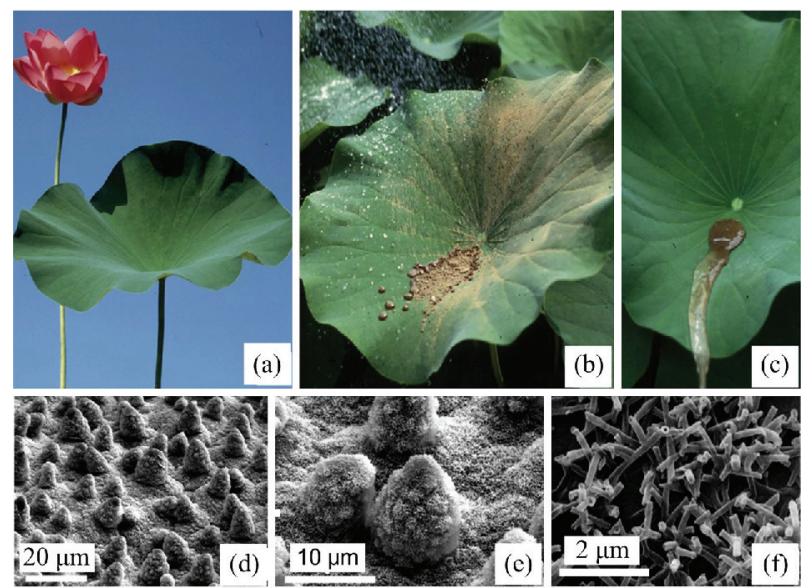

Fig. 1 Superhydrophobic lotus leaf surface. (a) Macroscopic appearance of the surface; (b) and (c) self-cleaning property; (d-f) SEM photographs of the lotus leaf surface at different multiples $^{[166]}$ (Copyright 2009 Elsevier).
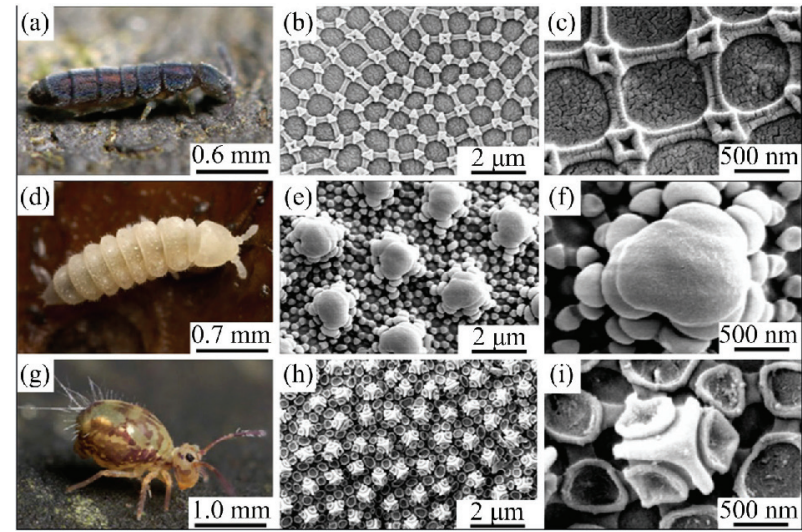

Fig. 2 Surfaces of different types of superoleophobic springtails. $(\mathrm{a}-\mathrm{c})$ Vertagopus arboreus and SEM images of its surface; $(\mathrm{d}-\mathrm{f})$ Kalaphorura burmeisteri and SEM images of its surface; (g-i) $D$. ornata and SEM images of its surface ${ }^{[170]}$ (Copyright 2013 Springer).

by both polar and non-polar liquids including water, methanol, ethanol, hexadecane, and tridecane instead of dodecane and hexane. Researchers have recently reported chemical components of the cuticle surface of Tetrodontophora bielanensis ${ }^{[172]}$. They observed that the stratum corneum region was composed of three different layers of matter, that is, the inner layer of the stratum corneum was comprised of porous layered chitin, and the stratum corneum structure consisted of proteins such as glycine, tyrosine and serine, the top layer comprised lipids such as hydrocarbon acids, esters, steroids and terpenoids. These findings provide new concepts for the construction of superoleophobic surfaces that do not contain fluorine-containing materials.

\subsection{Striped fish and shark}

Jiang et al. ${ }^{[163]}$ reported anisotropic underwater superoleophobicity on the surface of the striped fish skin (Fig. 3a). Oil droplets in water environment rolled freely from head to tail, but faced difficulty in the reverse direction resulting from the presence of the directional hook-and-thorn structures on the surface (Fig. 3b and Fig. 3c). The anisotropic underwater superoleophobicity of the striped fish skin prevented oil from accumulating on its head, thus the fish could survive in oil-contaminated seawater. Bhushan et al. ${ }^{[23,173,174]}$ reported that shark skin had underwater superoleophobicity, and was covered with the toothed scale structures (Figs. 3d and 3e) with grooves and ribs. Since the grooves were arranged parallel to the water flowing direction, the resistance of sharks when swimming was weakened by the decrease of the eddy current. Therefore, the presence of these structures could help to increase swimming speed of sharks ${ }^{[175]}$.

Superhydrophobic, superoleophobic and underwater superoleophobic properties exhibited by various organisms in nature provide an important basis for further research on the applications. The easiest way to obtain multi-functional and man-made materials is to imitate nature, and then combine and optimize two or more seemingly distinct concepts found in nature to create functional materials with excellent properties. In fact, nature has given birth to a number of plants, insects and animals that are capable of repelling water, and even repel polar and non-polar liquids with lower surface tension. Research on bionics is still in its infancy, but this bio-inspired research has already become one of the hotspots demonstrating a very broad application prospect.

\section{Modeling and design}

Wettability results from interfacial interactions between a liquid and a solid surface. A force balance between adhesion and cohesion determines the degree of wetting of a surface ${ }^{[176]}$. However, the asymmetric cohesion among such droplet molecules generates surface tension, resulting in a reduced interaction area when the droplet and the solid surface are brought together. Up to now, some unique wettability phenomena bring new challenges to the traditional wettability theory, such as 
(a)
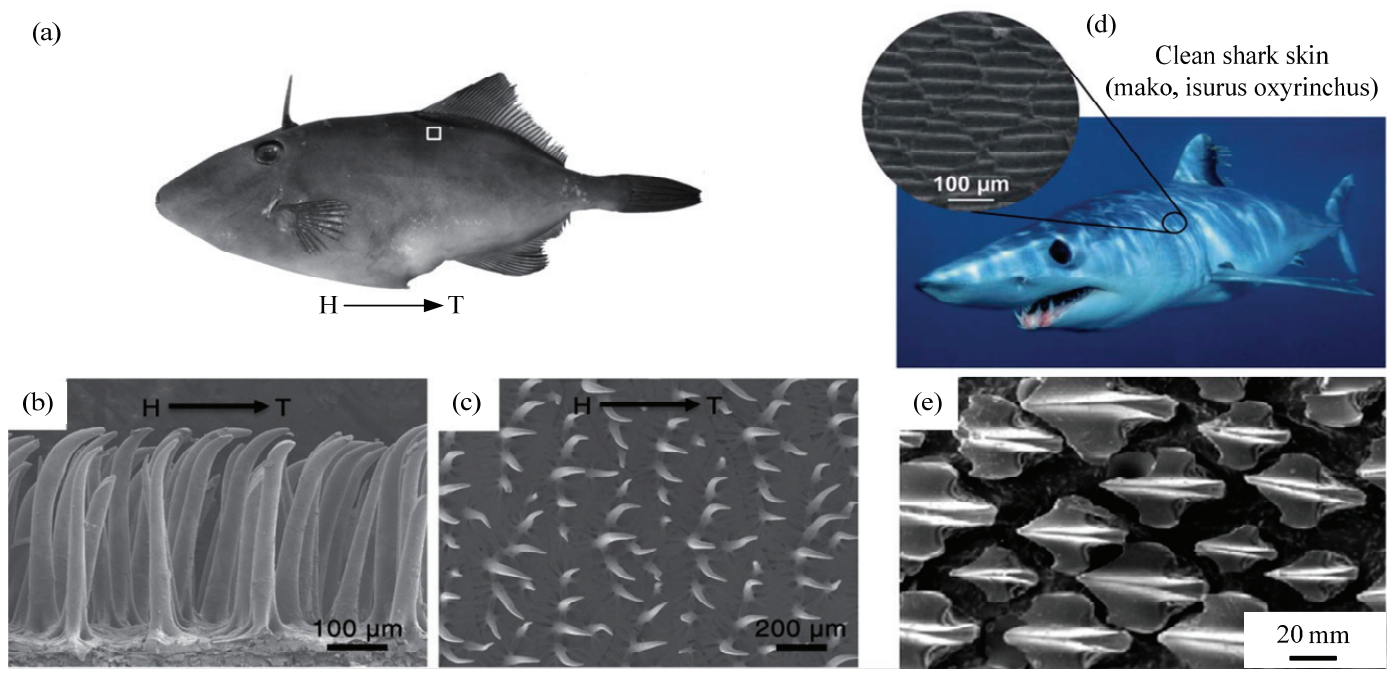

Fig. 3 Underwater superoleophobic striped fish and shark surface. (a) Striped fish; (b) shark; (c) SEM images of striped fish skin surface $^{[163]}$ (Copyright 2014 Wiley-VCH); (d) microstructure and its model of shark skin surface ${ }^{[23]}$ (Copyright 2013 RSC).

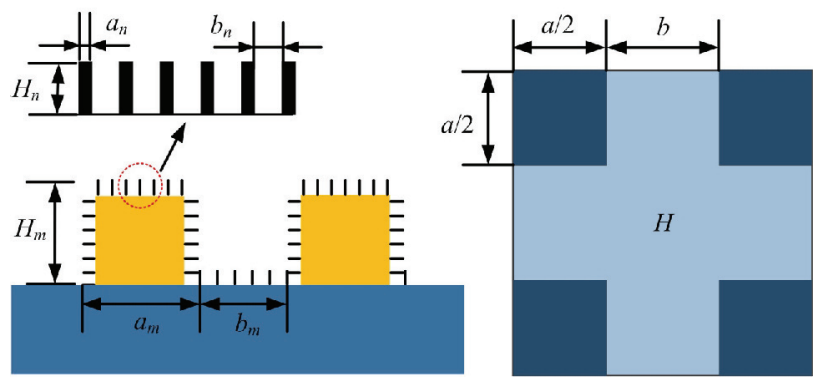

Fig. 4 Square-column two-scale structural model in which the cross-section of the square-column structure is $a \times a$. (a) A two-scale micro- and nano-scale square column structure; (b) a top view of a periodic structure.

Young's equation, Wenzel model and Cassie mod$\mathrm{el}^{[177-180]}$. Therefore, in this section, we try to clarify some basic concepts to understand unique wettability. It is expected to provide theoretical reference for the design and research of functional materials with special wettability.

\subsection{Modeling and design of superhydrophobic property}

With the in-depth research of the structure of the lotus leaf, Jiang et al. found that the surface has micronsized mastoid structures and nano-sized protrusion structures, which are key factors for achieving the superhydrophobicity ${ }^{[6]}$. Subsequently, Patanker et al. ${ }^{[181]}$ used the lotus leaf as an example to establish a two-scale structural model (Fig. 4). For the first-order micro-sized structure, the area of the square column is $a_{m} \times a_{m}$ and the height is $H_{m}$. The Cassie equation of the surface of the micro-sized structure is expressed as:

$$
\cos \theta_{C}^{m}=A_{m}\left(1+\cos \theta_{e}\right)-1,
$$

where $\theta_{e}$ is the contact angle of the smooth surface, $\theta_{C}^{m}$ is the contact angle of the first-order micro-sized structure surface in the Cassie state, and $A_{m}$ is:

$$
A_{m}=\frac{1}{\left[\left(b_{m} / a_{m}\right)+1\right]^{2}} .
$$

For the second-order nano-sized structure, the area of the square column is $a_{n} \times a_{n}$ and the height is $H_{n}$, then the Cassie equation of the surface of the nano-sized structure is expressed as:

$$
\cos \theta_{C}^{n}=A_{n}\left(1+\cos \theta_{C}^{m}\right)-1,
$$

where $\theta_{C}^{n}$ is the contact angle of the second-order nanosized structure surface in the Cassie state, and $A_{n}$ is:

$$
A_{n}=\frac{1}{\left[\left(b_{n} / a_{n}\right)+1\right]^{2}} .
$$

The above theoretical results show that for a double-scale structured surface, the contact angle of the droplet on the second-order structure is significantly increased compared to the first-order structure. Moreover, the characteristics of the double-scale structure help to keep the droplet in a stable Cassie state, making it easier to achieve the "Lotus Effect". 

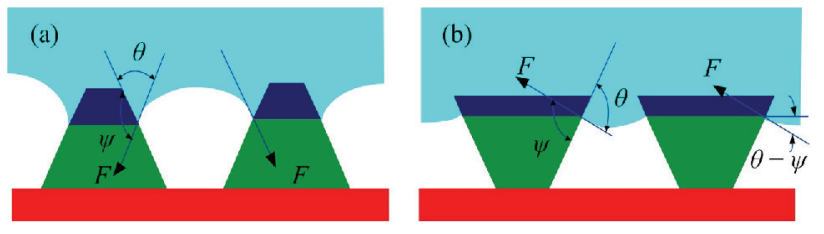

Fig. 5 Schematic diagram of the wetting behavior of liquids on two different structural surfaces. (a) A positive trapezoidal structure; (b) an inverted trapezoidal structure.

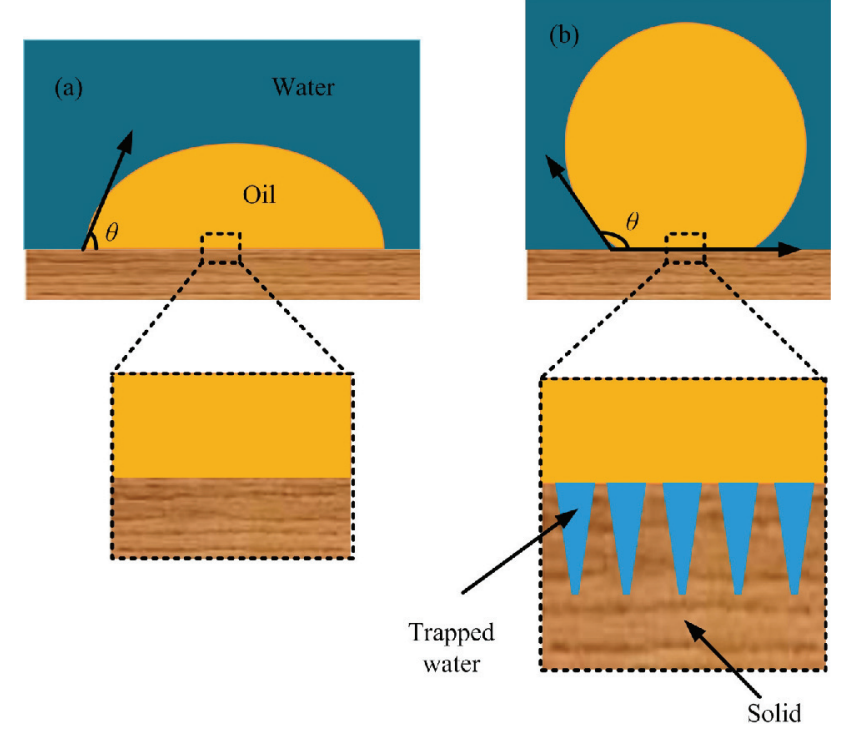

Fig. 6 Schematic diagram of the wetting model of oil in an aqueous environment. (a) Young model; (b) Cassie model.

\subsection{Modeling and design of superoleophobic prop- erty}

It is known that the highly ordered structures on the surface of springtails make their skins superoleophobic and resistant to wetting by oil. Since the surface tension of the oil is less than that of water, especially hexadecane, dodecane, etc., which have a surface tension in the range of $20 \mathrm{mN} \cdot \mathrm{m}^{-1}-30 \mathrm{mN} \cdot \mathrm{m}^{-1}$. Therefore, to exclude this type of oil droplets, surface roughness and surface free energy must be more strictly controlled. According to Young's equation, when the oil droplet is placed on a solid surface, the equation is as:

$$
\cos \theta_{\mathrm{o}}=\frac{\gamma_{\mathrm{so}}-\gamma_{\mathrm{sa}}}{\gamma_{\mathrm{ao}}}
$$

where $\theta_{\mathrm{o}}$ is the oil contact angle on the solid surface, and $\gamma_{\mathrm{sa}}, \gamma_{\mathrm{so}}$ and $\gamma_{\mathrm{ao}}$ are the surface tensions of solid-air, solid-oil and air-oil, respectively. From the Eq. 5, it is known that the oleophobic surface can be obtained only when $\gamma_{\mathrm{so}}>\gamma_{\mathrm{sa}}$. In addition, fluorine- or perfluorinated modifiers can further improve the oleophobicity of the surface $^{[182]}$.

Although the Cassie model can effectively evaluate the superoleophobicity of conventional structural surfaces, the Wenzel state on the surfaces will be formed for liquids with surface tensions below $30 \mathrm{mN} \cdot \mathrm{m}^{-1}$. In response to this problem, Tuteja et al. ${ }^{[183]}$ designed the surface microstructure and proposed for the first time that the key to the preparation of the superoleophobic surface is the re-entrant texture. In order to qualitatively explain the importance of the re-entrant texture, the wetting behaviors of the liquid on the surface of the positive trapezoidal structure (structure angle $\psi>90^{\circ}$ ) and the inverted trapezoidal structure (called re-entrant texture, structure angle $\psi<90^{\circ}$ ) were analyzed (Fig. 5). The surface will produce a stable Cassie state only when $\theta>\psi^{[184-186]}$. The main reason is that if $\theta<\psi$, the gas-liquid interface will produce downward traction under the action of capillary force, which will cause the liquid to penetrate into the solid microstructure to form a Wenzel state. Therefore, the well-designed re-entrant texture on the surface can form a stable superoleophobic property.

\subsection{Modeling and design of underwater superoleo- phobic property}

When the fish scales are contact with the oil droplet, an oil-water-solid interface is formed with the participation of water trapped in the microstructural fish scales. This new composite interface shows underwater superoleophobicity. Although Young's equation was originally applied in air, it has been applied to an oil droplet on a solid surface under water. According to Young's equation, we could get the following equation:

$$
\cos \theta_{\text {ow }}=\frac{\gamma_{\text {oa }} \cos \theta_{\mathrm{o}}-\gamma_{\mathrm{wa}} \cos \theta_{\mathrm{w}}}{\gamma_{\mathrm{ow}}},
$$

where, $\gamma_{\text {wa }}, \gamma_{\text {oa }}$ and $\gamma_{\text {ow }}$ are the surface tensions of water-air, oil-air and oil-water, respectively, $\theta_{\mathrm{w}}$ is the water contact angle in air, $\theta_{\mathrm{o}}$ is the oil contact angle in air, and $\theta_{\text {ow }}$ is the oil contact angle in water (Fig. 6a). Through the Eq. 6, materials that are hydrophilic in air can be used to attempt to prepare underwater oleophobic surfaces.

For a rough surface, the Cassie equation in the 
water environment can be expressed as:

$$
\cos \theta_{\text {ow }}^{C}=f \cos \theta_{\text {ow }}+f-1,
$$

where $f$ is the ratio of the water-solid interface occupied by the solid surface, and $\theta_{\mathrm{ow}}^{C}$ and $\theta_{\mathrm{ow}}$ are the underwater contact angles of the oil droplet on the structural and smooth surfaces, respectively. When the structural surface is immersed in water, the water will fall into the microstructure, resulting in the formation of a water-oil-solid composite interface. The water that has fallen into the microstructure prevents the oil droplet from penetrating into the microstructure (Fig. 6b).

\subsection{Design of slippery liquid-infused surfaces}

It is known that superhydrophobic surfaces have problems such as poor mechanical stability and short life, which reduce their value in practical applications. In 2011, Aizenberg et al.$^{[187]}$ reported for the first time a slippery liquid-infused surface by mimicking pitcher plants. The obtained surface has the advantages of self-repair and high pressure resistance, and effectively solves the issues encountered in the use of the superhydrophobic surface.

The slippery liquid-infused surface mainly utilizes the lubricating liquid in the microstructure to resist the invasion of other liquids. To this end, the design of the surface must satisfy the following conditions: First, the infiltrated lubricating oil and the working liquid are incompatible. Second, the adsorption force of the lubricating oil and the surface should be greater than the adsorption force of the working liquid and the surface. Last, there are a large number of micro-scale structures to increase the adsorption surface area and thus store more lubricant.

In order to satisfy the second principle, Smith et $a l{ }^{[188]}$ analyzed the surface energy. When there is a working liquid on the surface, the working liquid, the lubricating oil and the surface have three contact states. $W 1$ means that the working fluid completely replaces the lubricating oil, $W 2$ is partially replaced, and $W 3$ indicates that working fluid cannot replace lubricating oil, as shown in Fig. 7. The surface energy per unit area in the three states is:

$$
E_{W 1}=r \gamma_{\mathrm{sw}}
$$

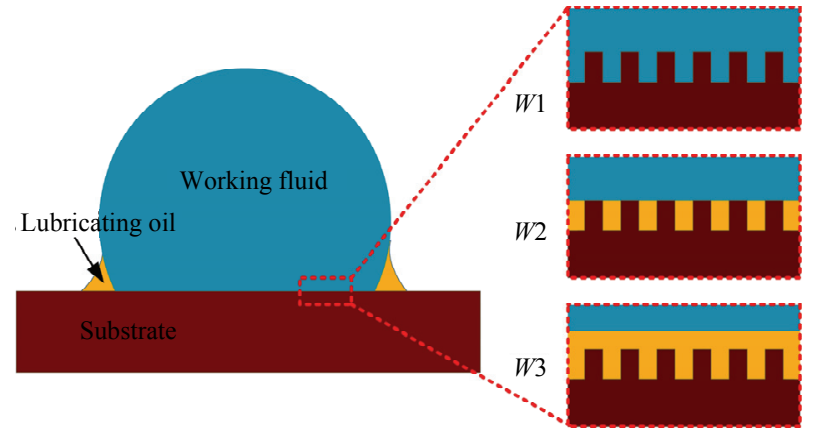

Fig. 7 Design principle of slippery liquid-infused surface.

$$
\begin{gathered}
E_{W 2}=(r-\varphi) \gamma_{\mathrm{os}}+\varphi \gamma_{\mathrm{sw}}+(1-\varphi) \gamma_{\mathrm{ow}}, \\
E_{W 3}=\gamma_{\mathrm{ow}}+r \gamma_{\mathrm{os}},
\end{gathered}
$$

where $\gamma_{\mathrm{sw}}$ is the surface tension between the surface and the working liquid, $\gamma_{\mathrm{so}}$ is the surface tension between the surface and the lubricating oil, and $\gamma_{o w}$ is the surface tension between the lubricating oil and the working liquid. Therefore, the condition that the working fluid does not replace the lubricating oil is that the surface energy $E_{W 3}$ is the smallest:

$$
E_{W 3}<E_{W 1}, E_{W 2} .
$$

\section{Preparation of biomimetic superlyophobic surfaces on metallic substrates}

The preparation of biomimetic superlyophobic surfaces on metal substrates is an integral part of the study on the wettability of solid surfaces. Two conditions are usually required for the formation of biomimetic superlyophobic surfaces on metallic materials: one is that the surface has certain microstructure, and besides it has very low surface energy. Various methods have been proposed by researchers over the past two decades to prepare microstructures on metallic substrates with superlyophobicity, such as femto/pico/nanosecond laser processing method, electric spark machining method, electrochemical etching/deposition/anodization method, chemistry etching/deposition method, spray method and electrospinning method. Table 2 summaries these innovate techniques applied to different surfaces.

\subsection{Superhydrophobic metallic surfaces}

(1) Femto/pico/nanosecond laser processing

Kietzig et al. ${ }^{[236]}$ produced two-scale roughness on 
Table 2 Summary of various fabrication methods applied to different surfaces

\begin{tabular}{|c|c|c|c|c|c|c|}
\hline Wetting property & Technique & Advantage/disadvantage & Material & Morphology & $\mathrm{CA} / \mathrm{SA}$ & Refs. \\
\hline \multirow{22}{*}{ Superhydrophobicity } & \multirow{3}{*}{$\begin{array}{l}\text { Femtosecond } \\
\text { laser processing }\end{array}$} & \multirow{3}{*}{$\begin{array}{l}\text { High processing precision, stable microstructure and good } \\
\text { surface quality, but high cost, low processing efficiency, high } \\
\text { environment requirements, and difficult to apply to large-scale } \\
\text { production }\end{array}$} & Aluminum & Nanoripple structures & $153^{\circ}$ & [189] \\
\hline & & & Platinum & $\begin{array}{l}\text { Parallel micro-grooves } \\
\text { and extensive nanostruc- } \\
\text { tures }\end{array}$ & $158^{\circ}$ & [190] \\
\hline & & & Nickel & $\begin{array}{l}\text { Microcolumn and nano- } \\
\text { particles }\end{array}$ & $161.3^{\circ}$ & [191] \\
\hline & \multirow{2}{*}{$\begin{array}{l}\text { Picosecond laser } \\
\text { processing }\end{array}$} & \multirow{2}{*}{$\begin{array}{l}\text { Higher production efficiency, stable microstructure, and con- } \\
\text { trollable microstructure, but still unsatisfactory economics, and } \\
\text { no advantage in large-scale production }\end{array}$} & $\begin{array}{l}\text { Aluminum } \\
\text { alloy }\end{array}$ & $\begin{array}{l}\text { Micro-gratings and cau- } \\
\text { liflower-like protrusions }\end{array}$ & $162^{\circ}$ & [192] \\
\hline & & & Nickel & $\begin{array}{l}\text { 2D array micro-bumps } \\
\text { with nano-ripples }\end{array}$ & $159.3^{\circ}$ & [193] \\
\hline & \multirow{3}{*}{$\begin{array}{l}\text { Nanosecond } \\
\text { laser processing }\end{array}$} & \multirow{3}{*}{$\begin{array}{c}\text { Low cost, high processing speed, low environment require- } \\
\text { ments, suitable to apply to large-scale production, but low } \\
\text { quality surface, relatively poor controllability }\end{array}$} & Copper & $\begin{array}{l}\text { Cotton-like nanostruc- } \\
\text { tures }\end{array}$ & $>160^{\circ}$ & [194] \\
\hline & & & Nitinol alloy & Grid pattern & $154.4^{\circ}$ & [195] \\
\hline & & & $\begin{array}{l}\text { 316L stainless } \\
\text { steel }\end{array}$ & Gaussian micro hole & $153.2^{\circ}$ & [196] \\
\hline & \multirow{3}{*}{$\begin{array}{l}\text { Electrical dis- } \\
\text { charge machin- } \\
\text { ing method }\end{array}$} & \multirow{3}{*}{$\begin{array}{c}\text { Suitable for complex surface machining and high hardness } \\
\text { metal processing, good anti-wear ability, high material utiliza- } \\
\text { tion and not limited to small areas, but relatively lower } \\
\text { processing efficiency and precision }\end{array}$} & Copper & T-shaped grooves & $152.5^{\circ}$ & [197] \\
\hline & & & Copper foil & $\begin{array}{l}\text { Microscale craters and } \\
\text { nanoparticles }\end{array}$ & $171^{\circ}$ & [198] \\
\hline & & & Titanium alloy & $\begin{array}{l}\text { Randomly-distributed } \\
\text { hemispherical features }\end{array}$ & - & [199] \\
\hline & \multirow[b]{2}{*}{$\begin{array}{l}\text { Electrochemical } \\
\text { etching }\end{array}$} & \multirow[b]{2}{*}{$\begin{array}{c}\text { Controlled, less hazardous, and more environmentally safe, but } \\
\text { energy consumption }\end{array}$} & Titanium & $\begin{array}{l}\text { Micro- and nano-scale } \\
\text { structures }\end{array}$ & $162.2^{\circ}$ & {$[200]$} \\
\hline & & & Zinc & $\begin{array}{l}\text { Micro-scale pits, protru- } \\
\text { sions and numerous } \\
\text { nano-scale dendrite } \\
\quad \text { structures }\end{array}$ & $165.3^{\circ}$ & [201] \\
\hline & $\begin{array}{c}\text { Electrochemical } \\
\text { deposition }\end{array}$ & $\begin{array}{l}\text { Fast, large-scale, low-cost and easily controlled, but weak } \\
\text { binding force with substrate and energy consumption }\end{array}$ & Copper mesh & $\begin{array}{l}\text { Micro- and nano-scale } \\
\text { structures }\end{array}$ & $154.1^{\circ}$ & {$[202]$} \\
\hline & \multirow{2}{*}{$\begin{array}{l}\text { Electrochemical } \\
\text { anodization }\end{array}$} & \multirow{2}{*}{$\begin{array}{l}\text { Fast, large-scale, and controlled, but energy consumption, } \\
\text { limited to the process of specific metal (valve metal) materials, } \\
\text { and usually uses fluorine or acid-alkaline solutions, which is } \\
\text { highly polluting to the environment }\end{array}$} & Titanium alloy & Micro-pore structures & $158.5^{\circ}$ & {$[203]$} \\
\hline & & & Copper & $\begin{array}{l}\text { Nanoneedle-like struc- } \\
\text { tures }\end{array}$ & $169^{\circ}$ & {$[204]$} \\
\hline & \multirow{2}{*}{$\begin{array}{l}\text { Chemical etch- } \\
\text { ing }\end{array}$} & \multirow{2}{*}{$\begin{array}{l}\text { Widely used in surface processing, convenient and easy to } \\
\text { manipulate, but inaccurate to control morphology, somewhat } \\
\text { hazardous, and not an environment-friendly method }\end{array}$} & Stainless steel & $\begin{array}{l}\text { Petal-like microstructure } \\
\text { nano-scale structure }\end{array}$ & $168^{\circ}$ & {$[205]$} \\
\hline & & & Aluminum & $\begin{array}{l}\text { Hydrangea-like mi- } \\
\text { cro/nano structures }\end{array}$ & $161.3^{\circ}$ & {$[206]$} \\
\hline & \multirow{2}{*}{$\begin{array}{l}\text { Chemical depo- } \\
\text { sition }\end{array}$} & \multirow{2}{*}{$\begin{array}{c}\text { Convenient and easy to manipulate, but somewhat high cost by } \\
\text { using precious metals such as gold and silver }\end{array}$} & $\begin{array}{l}\text { Aluminum } \\
\text { alloy }\end{array}$ & $\begin{array}{l}\text { Micron-sized pores and } \\
\text { nano-sized fishbone-like } \\
\text { dendrites }\end{array}$ & $159^{\circ}$ & [208] \\
\hline & & & Copper & $\begin{array}{l}\text { Micro-sized spherical } \\
\text { particles and nano-sized } \\
\text { protrusions }\end{array}$ & $156^{\circ}$ & [209] \\
\hline & \multirow{2}{*}{$\begin{array}{l}\text { Spraying me- } \\
\text { thod }\end{array}$} & \multirow{2}{*}{$\begin{array}{c}\text { Simple, large area coverage and applicable for a variety of } \\
\text { substrates, but unstable structure and hard to fine tune surface } \\
\text { morphology }\end{array}$} & Copper & Silver thiolate particles & $167.8^{\circ}$ & {$[210]$} \\
\hline & & & $\begin{array}{l}\text { Aluminum } \\
\text { alloy }\end{array}$ & $\begin{array}{l}\text { Micro-scale roughness } \\
\text { and nanoparticles }\end{array}$ & $162^{\circ}$ & [211] \\
\hline \multirow{7}{*}{ Superoleophobicity } & $\begin{array}{l}\text { Electrical dis- } \\
\text { charge machin- } \\
\text { ing method }\end{array}$ & $\begin{array}{c}\text { Suitable for complex surface machining and high hardness } \\
\text { metal processing, good anti-wear ability, high material utiliza- } \\
\text { tion and not limited to small areas, but relatively lower } \\
\text { processing efficiency and precision }\end{array}$ & $\mathrm{Al} / \mathrm{Mg}$ alloy & $\begin{array}{l}\text { Micro-craters and } \\
\text { terrace-like nanostruc- } \\
\text { tures }\end{array}$ & - & {$[212]$} \\
\hline & $\begin{array}{l}\text { Electrochemical } \\
\text { etching }\end{array}$ & $\begin{array}{c}\text { Controlled, less hazardous, and more environmentally safe, but } \\
\text { energy consumption }\end{array}$ & Zinc & $\begin{array}{l}\text { Micro- and nano-scale } \\
\text { structures }\end{array}$ & - & {$[213]$} \\
\hline & $\begin{array}{l}\text { Electrochemical } \\
\text { deposition }\end{array}$ & $\begin{array}{l}\text { Fast, large-scale, low-cost and easily controlled, but weak } \\
\text { binding force with substrate and energy consumption }\end{array}$ & $\mathrm{Ni} / \mathrm{Cu}$ & $\begin{array}{l}\text { Nano-Ni pyra- } \\
\text { mid/micro-Cu cone } \\
\text { structures }\end{array}$ & - & {$[214]$} \\
\hline & \multirow{2}{*}{$\begin{array}{l}\text { Electrochemical } \\
\text { anodization }\end{array}$} & \multirow{2}{*}{$\begin{array}{l}\text { Fast, large-scale, and controlled, but energy consumption, } \\
\text { limited to the process of specific metal (valve metal) materials, } \\
\text { and usually uses fluorine or acid-alkaline solutions, which is } \\
\text { highly polluting to the environment }\end{array}$} & Titanium alloy & $\begin{array}{l}\text { Micro-scale protrusions } \\
\text { and nano-scale structures }\end{array}$ & - & {$[215]$} \\
\hline & & & $\begin{array}{l}\text { Magnesium } \\
\text { alloy }\end{array}$ & $\begin{array}{l}\text { Micro/nanoscale caulif- } \\
\text { lower-like cluster binary } \\
\text { structure }\end{array}$ & - & [216] \\
\hline & \multirow{2}{*}{$\begin{array}{l}\text { Chemical etch- } \\
\text { ing }\end{array}$} & \multirow{2}{*}{$\begin{array}{l}\text { Widely used in surface processing, convenient and easy to } \\
\text { manipulate, but inaccurate to control morphology, somewhat } \\
\text { hazardous, and not an environment-friendly method }\end{array}$} & Aluminum & $\begin{array}{l}\text { Microstep and nanoreti- } \\
\text { cula structures }\end{array}$ & - & {$[217]$} \\
\hline & & & Al-Mg alloy & $\begin{array}{c}\text { Labyrinth-like micro- } \\
\text { structures and twisty } \\
\text { nanoflakes }\end{array}$ & - & [218] \\
\hline
\end{tabular}


Table 2 Continued

\begin{tabular}{|c|c|c|c|c|c|c|}
\hline Wetting property & Technique & Advantage/disadvantage & Material & Morphology & $\mathrm{CA} / \mathrm{SA}$ & Refs. \\
\hline & $\begin{array}{l}\text { Chemical depo- } \\
\text { sition }\end{array}$ & $\begin{array}{c}\text { Simple, large area coverage and applicable for a variety of } \\
\text { substrates, but unstable structure and hard to fine tune surface } \\
\text { morphology }\end{array}$ & Stainless steel & $\begin{array}{l}\text { Micro/nano-scale origa- } \\
\text { mi-ball-like structures }\end{array}$ & - & [219] \\
\hline & $\begin{array}{l}\text { Spraying me- } \\
\text { thod }\end{array}$ & $\begin{array}{l}\text { Simple, large area coverage and applicable for a variety of } \\
\text { substrates, but unstable structure and hard to fine tune surface } \\
\text { morphology }\end{array}$ & Carbon steel & $\begin{array}{l}\text { Micro- and nano-scale } \\
\text { structures }\end{array}$ & - & [220] \\
\hline \multirow{9}{*}{$\begin{array}{l}\text { Underwater supero- } \\
\text { leophobicity }\end{array}$} & \multirow{2}{*}{$\begin{array}{l}\text { Femtosecond } \\
\text { laser processing }\end{array}$} & \multirow{2}{*}{$\begin{array}{c}\text { High processing precision, stable microstructure and good } \\
\text { surface quality, but high cost, low processing efficiency, high } \\
\text { environment requirements, and difficult to apply to large-scale } \\
\text { production }\end{array}$} & Copper & $\begin{array}{l}\text { Micro- and nano-scale } \\
\text { structures }\end{array}$ & - & [221] \\
\hline & & & Stainless steel & $\begin{array}{l}\text { Micro-cavities and nano- } \\
\text { particles }\end{array}$ & - & [222] \\
\hline & $\begin{array}{l}\text { Electrochemical } \\
\text { etching }\end{array}$ & $\begin{array}{c}\text { Controlled, less hazardous, and more environmentally safe, but } \\
\text { energy consumption }\end{array}$ & Copper & Curled plate-like structure & - & [223] \\
\hline & $\begin{array}{l}\text { Electrochemical } \\
\text { deposition }\end{array}$ & $\begin{array}{l}\text { Fast, large-scale, low-cost and easily controlled, but weak } \\
\text { binding force with substrate and energy consumption }\end{array}$ & Copper mesh & $\begin{array}{l}\text { Micro-nano-sized small } \\
\text { breast }\end{array}$ & - & [224] \\
\hline & \multirow{2}{*}{$\begin{array}{l}\text { Electrochemical } \\
\text { anodization }\end{array}$} & \multirow{2}{*}{$\begin{array}{l}\text { Fast, large-scale, and controlled, but energy consumption, } \\
\text { limited to the process of specific metal (valve metal) materials, } \\
\text { and usually uses fluorine or acid-alkaline solutions, which is } \\
\text { highly polluting to the environment }\end{array}$} & Titanium & $\begin{array}{l}\text { Pinecone-like microscale } \\
\text { protrusions and nano- } \\
\text { sheets }\end{array}$ & - & [225] \\
\hline & & & Copper mesh & $\begin{array}{l}\text { Layered cauliflower-like } \\
\text { structure }\end{array}$ & - & [226] \\
\hline & $\begin{array}{l}\text { Chemical etch- } \\
\text { ing }\end{array}$ & $\begin{array}{l}\text { Widely used in surface processing and easy to manipulate, but } \\
\text { somewhat hazardous, and not an environment-friendly method }\end{array}$ & Copper foils & $\begin{array}{l}\text { Dandelion-like micro- } \\
\text { structures }\end{array}$ & - & [227] \\
\hline & \multirow{2}{*}{$\begin{array}{l}\text { Spraying me- } \\
\text { thod }\end{array}$} & \multirow{2}{*}{$\begin{array}{c}\text { Simple, large area coverage and applicable for a variety of } \\
\text { substrates, but unstable structure and hard to fine tune surface } \\
\text { morphology }\end{array}$} & Copper & Cauliflower shape & - & [228] \\
\hline & & & Stainless steel & $\begin{array}{l}\text { Micro- and nano-scale } \\
\text { structures }\end{array}$ & - & [229] \\
\hline \multirow{7}{*}{$\begin{array}{l}\text { Slippery liquid- } \\
\text { infused surfaces }\end{array}$} & & High processing precision, stable microstructure and good & Titanium & Spike structures & - & [230] \\
\hline & $\begin{array}{l}\text { Femtosecond } \\
\text { laser processing }\end{array}$ & $\begin{array}{l}\text { surface quality, but high cost, low processing efficiency, high } \\
\text { environment requirements, and difficult to apply to large-scale } \\
\text { production }\end{array}$ & $\begin{array}{l}\text { 316L 2B } \\
\text { stainless steel }\end{array}$ & $\begin{array}{l}\text { An uneven relief with } \\
\text { numerous grain bounda- } \\
\text { ries }\end{array}$ & $2^{\circ}$ & [231] \\
\hline & $\begin{array}{l}\text { Nanosecond } \\
\text { laser processing }\end{array}$ & $\begin{array}{l}\text { Low cost, high processing speed, low environment require- } \\
\text { ments, suitable to apply to large-scale production, but low } \\
\text { quality surface, relatively poor controllability }\end{array}$ & Carbon steel & $\begin{array}{l}\text { Stacked micro/nano } \\
\text { structures }\end{array}$ & $2.5^{\circ}$ & [232] \\
\hline & $\begin{array}{l}\text { Electrochemical } \\
\text { etching }\end{array}$ & $\begin{array}{l}\text { Controlled, less hazardous, and more environmentally safe, but } \\
\text { energy consumption }\end{array}$ & Zinc & $\begin{array}{l}\text { Needle-like and flake } \\
\text { nanostructures }\end{array}$ & $10^{\circ}$ & [233] \\
\hline & $\begin{array}{l}\text { Electrochemical } \\
\text { deposition }\end{array}$ & $\begin{array}{l}\text { Fast, large-scale, low-cost and easily controlled, but weak } \\
\text { binding force with substrate and energy consumption }\end{array}$ & Titanium & Dendritic structure & $8^{\circ}$ & [234] \\
\hline & $\begin{array}{l}\text { Electrochemical } \\
\text { etching and } \\
\text { oxidation }\end{array}$ & \multirow{2}{*}{$\begin{array}{c}\text { Fast, large-scale, low-cost and easily controlled, but energy } \\
\text { consumption and multiple steps }\end{array}$} & Aluminum & $\begin{array}{l}\text { Micron-sized stepped } \\
\text { structure and nano-sized } \\
\text { holes }\end{array}$ & $<5^{\circ}$ & [128] \\
\hline & $\begin{array}{l}\text { Electrochemical } \\
\text { deposition and } \\
\text { anodizing }\end{array}$ & & $\mathrm{Cu} / \mathrm{Zn}$ alloy & $\begin{array}{l}\text { Needle-like structure with } \\
\text { the porous feature }\end{array}$ & $11.3^{\circ}$ & [235] \\
\hline
\end{tabular}

$\mathrm{CA}=$ contact angle, $\mathrm{SA}=$ sliding angle. Water $\mathrm{CA}$ is used to quantitatively compare among superhydrophobic surfaces. For superoleophobic surfaces and underwater superoleophobic surfaces, the types of oils used by researchers to measure oil CAs in air or under water are varied, so we have not summarized them. In addition, the water SA is the main characteristic for slippery liquid-infused surfaces.

six metallic surfaces by the femtosecond laser treatment. The structured metallic surfaces initially showed superhydrophilic behavior and the surfaces were completely wetted. These surfaces gradually transformed from superhydrophilic to superhydrophobic state. By controlling laser processing parameters within a reasonable range, the water contact angle could be higher than $150^{\circ}$. Long et al..$^{[237]}$ constructed microstructures on aluminum surfaces by a picosecond laser processing method, and analyzed the mechanism of transition from superhydrophilicity to superhydrophobicity of microstructured surfaces under different environmental conditions. The obtained surfaces exhibited superhydrophi- licity immediately. However, the contact angle of water with the surfaces increased as time passed and eventually became superhydrophobic. Moreover, storage conditions had a great influence on this transition process. When the samples were stored in $\mathrm{CO}_{2}, \mathrm{O}_{2}$ and $\mathrm{N}_{2}$ environments, the wettability transition was inhibited. In contrast, the transition was accelerated in organic-rich air. Our group ${ }^{[238]}$ reported a simple two-step method to realize the creation of bio-inspired superhydrophobic surfaces on aluminum alloy samples by the nanosecond laser ablation. Many irregular micron-sized structures and nanostructures were observed on such surfaces (Figs. $8 \mathrm{a}$ and $8 \mathrm{~b}$ ). The water contact angle with the 


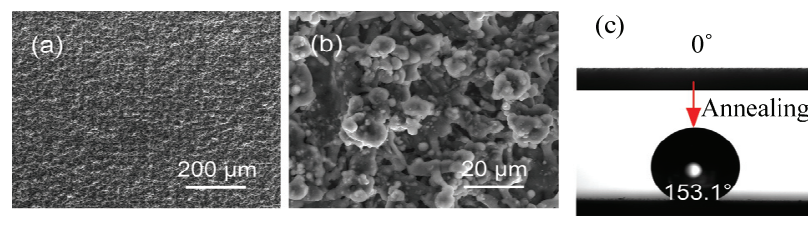

Fig. 8 (a) and (b) SEM images of aluminum alloy surface treated by the nanosecond laser with a scan spacing of $10 \mu \mathrm{m}$; (c) contact angle evolution of the fabricated surface before and after low-temperature annealing ${ }^{[238]}$ (Copyright 2019 Elsevier).

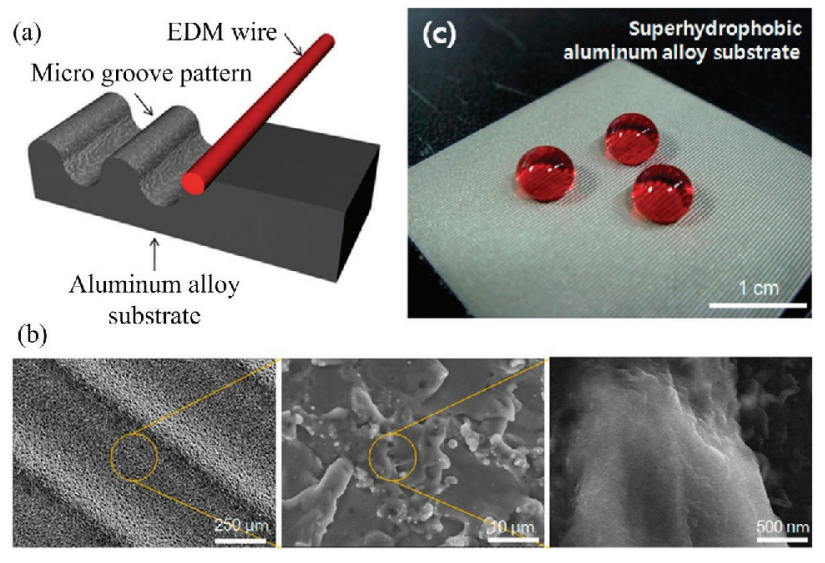

Fig. 9 Superhydrophobic aluminum alloy surface obtained using low-speed wire electrical discharge machining. (a) Schematic illustration to fabricate microstructures by wire electrical discharge machining; (b) SEM images of the machined surface with microstructures; (c) optical photograph of dyed droplets on the constructed aluminum alloy surface ${ }^{[239]}$ (Copyright 2012 ACS).

ablated surface was $0^{\circ}$ in the beginning and increased to $153.1^{\circ}$ following annealing of the samples with low temperature (Fig. 8c). When the water droplet fell on the ablated surface treated by low-temperature annealing, it could bounce up and did not sit on the surface during the whole process, demonstrating a good superhydrophobic property of ablated surface after low-temperature annealing.

\section{(2) Electrical discharge machining method}

Chung et al. ${ }^{[239]}$ reported a low-speed wire cut electrical discharge machining method for the construction of superhydrophobic aluminum alloy surfaces. The array groove structures having the wavelength of $200 \mu \mathrm{m}-500 \mu \mathrm{m}$ were obtained on the surfaces of the aluminum alloy by program controlling the running track of the wire (Fig. 9a), and the surfaces of the groove structures were also covered with the pit-like structures with a size of about several micrometers, thereby forming the micro-nanosacle structures (Fig. 9b). The static contact angle between the water drop and the surface was $156^{\circ}$ (Fig. 9c) and the contact angle hysteresis reached only $3^{\circ}$. Our group ${ }^{[240]}$ employed a singlestep high-speed wire electrical discharge machining method to fabricate superhydrophobic aluminum alloy surface. Rectangular sub-millimeter-scale trenches were processed on the surface of an aluminum alloy sample, and craters and bumps were found to be distributing uniformly over the surface of the rectangular trenches with porous nanostructures. The surface exhibited superhydrophobicity with a water contact angle of $158^{\circ}$.

\section{(3) Electrochemical etching/deposition/anodization}

$\mathrm{Xu}$ et al. ${ }^{[58]}$ generated microstructures on a magnesium alloy surface using electrochemical etching technology, and then achieved superhydrophobic property by fluorosilane modification. There was a layered roughness on the magnesium alloy surface, and the contact angle and rolling angle of a water droplet were $165.2^{\circ}$ and $2^{\circ}$ respectively. The effects of the processing time and unit area removal on wettability were studied. Additionally, the superhydrophobic surface had good corrosion resistance and durability. Liu et al. ${ }^{[241]}$ fabricated superhydrophobic surfaces with the micron/nanoscale structures on $\mathrm{Mg}-\mathrm{Sn}-\mathrm{Zn}$ alloy by electrochemical deposition technology. By controlling the electrodeposition time, it can be observed that the maximum contact angle between the water droplet and the surface was as high as $160.4^{\circ} \pm 0.7^{\circ}$. The superhydrophobic surface could also significantly improve the corrosion resistance of the substrates. Peng et al. ${ }^{[242]}$ produced a layered alumina pyramid rough structure on the surface of aluminum alloy by an electrochemical anodization method, which had excellent superhydrophobicity after low surface energy modification. Compared to the superhydrophobic surface treated by stearic acid, superhydrophobic surface modified by fluorosilane showed better chemical stability.

\section{(4) Chemical etching/deposition}

Qian et al. ${ }^{[243]}$ roughened aluminum, copper and zinc surfaces by chemical etching. The surface of the etched metal showed superhydrophobicity following fluorosilane modification. The water contact angle of the water droplet was larger than $150^{\circ}$, and the rolling angle 
of an $8 \mu \mathrm{L}$ water droplet was less than $10^{\circ}$. Choi et al. ${ }^{[244]}$ used three different types of alkaline chemical etching processes to fabricate micro-nanostructured aluminum surfaces. The surfaces produced acicular microstructures or micron-sized porous and nano-scale flake structures, the difference in the microstructures depended on the used chemical solution. After the hydrophobic treatment, the contact angle of deionized water with the etched aluminum surfaces was more than $150^{\circ}$ and the rolling angle was less than $5^{\circ}$. Song et al. ${ }^{[245]}$ proposed a chemical deposition method to prepare superhydrophobic surfaces on aluminum substrates. First, they immersed the aluminum plates into an aqueous solution of $\mathrm{CuSO}_{4}$ and $\mathrm{NaCl}$, and then modified with fluorosilane to decrease the surface energy. Pores, pore walls, dendrites, leaves and granular micro/nano-scale structures were observed on the constructed superhydrophobic surfaces with copper film, and the water contact angle and the sliding angle were $162.71^{\circ}$ and $0.51^{\circ}$, respectively. Qi et al. ${ }^{[246]}$ successfully applied silver nanoparticles to the surface of stainless steel needles by chemical substitution reaction using $\mathrm{AgNO}_{3}$ solution. The surface of the stainless steel needle formed porous micro/nanoscale structures. After modification with long chain thiol molecules, the water contact angle could reach $152^{\circ}$. Furthermore, the superhydrophobic stainless steel needles exhibited good antibacterial property.

\section{(5) Spraying method}

Li et al. ${ }^{[247]}$ sprayed the stearate particles formed by the reaction of inorganic salts with sodium stearate onto a stainless steel substrate to prepare a colored superhydrophobic stainless steel surface. The colorful superhydrophobic coating also maintained excellent chemical stability under acid and alkaline conditions, and retained a high resistance to corrosion. Guo et al ${ }^{[248]}$ used a smooth stainless steel mesh as a substrate (Figs. 10a and 10b) and sprayed synthesized acrylic polymer onto the surface to obtain microsphere structures with different scales (Figs. 10c and 10d). The untreated stainless steel mesh displayed hydrophobicity and lipophilicity, while the sprayed one presented superhydrophobicity and superlipophilicity with a water contact angle of $153^{\circ}$ and an oil contact angle of $0^{\circ}$ (Figs. 10e and 10f). Results showed that various water-soluble droplets (milk, tea,

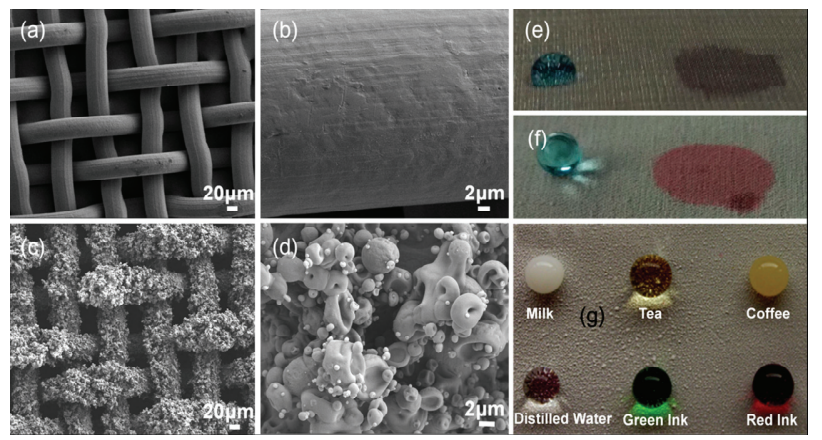

Fig. 10 Superhydrophobic stainless steel mesh obtained by spraying a coating. (a) and (b) SEM images of a smooth stainless steel mesh; (c) and (d) SEM images of a superhydrophobic stainless steel mesh; (e) and (f) wettability of stainless steel meshes before and after the spraying treatment; $(\mathrm{g})$ various droplets on the superhydrophobic stainless steel mesh ${ }^{[248]}$ (Copyright 2018 Springer).

coffee, etc.) all exhibited superlyophobicity (Fig. 10g). Moreover, the prepared stainless steel mesh was capable of separating mixed oil and water (n-hexane, isooctane, gas ether, kerosene and vegetable oil).

\subsection{Superoleophobic metallic surfaces}

At present, although superhydrophobic surfaces have great application prospects in the fields of selfcleaning, drag reduction and oil-water separation ${ }^{[8,10]}$, they have not achieved extensive practical applications. The main reason is that ordinary superhydrophobic surfaces do not have the resistance to oil wetting, and the surfaces will lose the superhydrophobicity once contaminated by oil ${ }^{[12,13]}$. Therefore, it is urgent to have a need to resist both water- and oil-wetting surfaces. It has been proved that the special re-entrant surface curvature and the further lowering of the surface free energy are necessary to produce a superoleophobic surface ${ }^{[183,184]}$. The following is an introduction to the recent developments in the fabrication of biomimetic superoleophobic metallic surfaces.

(1) Electrical discharge machining method

Weisensee et al. ${ }^{[249]}$ employed micro electrical discharge machining to fabricate five different micromushroom re-entrant structures on a low carbon steel surface. The water droplets on the surfaces formed nearly perfect spheres with the contact angle between $146^{\circ}$ and $162^{\circ}$ and contact angle hysteresis between $19^{\circ}$ and $35^{\circ}$. The contact angles of the oil droplet with the 


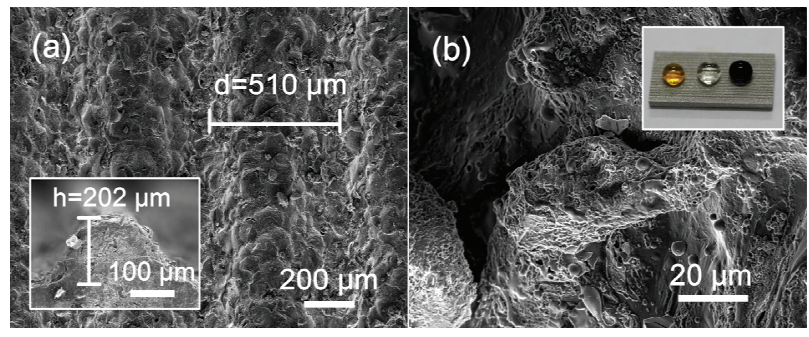

Fig. 11 Superoleophobic aluminum alloy surface obtained by high-speed wire electrical discharge machining method. (a) and (b) SEM images of the machined aluminum alloy surface with three-level composite structures, and the inset of (b) shows the droplets of water (right), glycerol (middle) and ethylene glycol (left) on the surface ${ }^{[250]}$ (Copyright 2015 Elsevier).
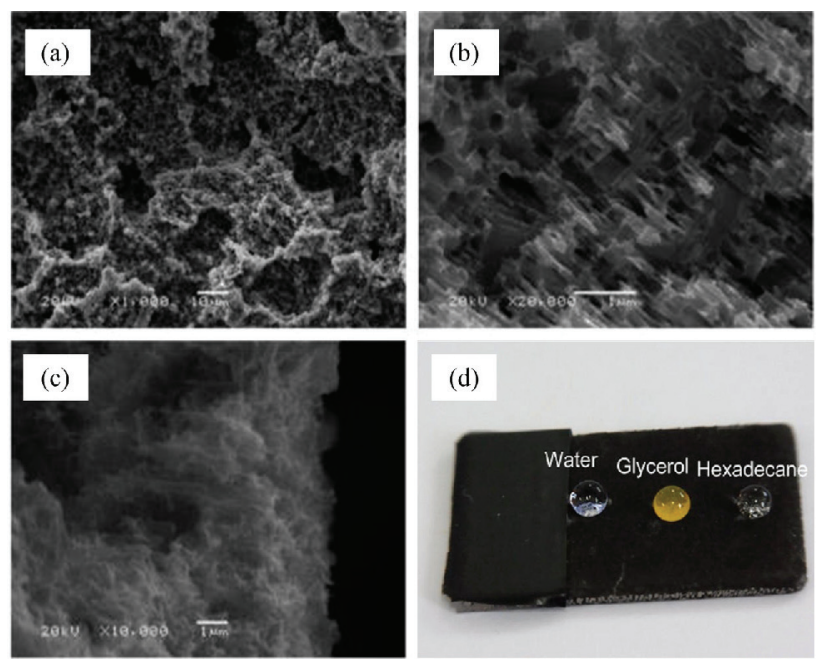

(d)

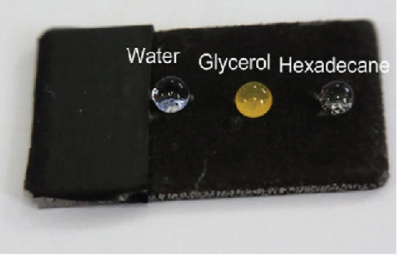

Fig. 12 Superoleophobic titanium alloy surface processed by electrochemical etching. (a) and (b) SEM images of the superoleophobic surface at two multiples; (c) cross-sectional SEM image of superoleophobic surface; (d) photograph of different droplets on the superoleophobic surface ${ }^{[251]}$ (Copyright 2013 ACS).

fabricated surfaces were in the range $106^{\circ}-152^{\circ}$, displaying the (super)oleophobicity. Our group ${ }^{[250]}$ used a high-speed wire electrical discharge machining method to fabricate sub-millimeter-scale structures on aluminum alloy surfaces (Figs. 11a and 11b). The fabricated V-shaped groove arrays with a hierarchical structure showed good superhydrophobicity and superoleophobicity following immersion in solution (Fig. 11c) with the contact angles of droplets of water, glycerol and ethylene glycol higher than $150^{\circ}$. The obtained surfaces still maintained good superoleophobicity after peel and mechanical tests (Fig. 11d). In addition, the obvious anisotropic sliding property was obtained on the surface.
(2) Electrochemical etching/deposition/anodization

Lu et al. ${ }^{[251]}$ prepared superhydrophobic and superoleophobic titanium surfaces by electrochemical etching. The fabricated superoleophobic surfaces had microscale bump and void structures (Fig. 12a) and nano-scale needle-like structures (Figs. 12b and 12c). The contact angles of water, glycerol, and hexadecane droplets were all greater than $150^{\circ}$ (Fig. 12d) and the sliding angle were only $1^{\circ}-2^{\circ}$. Moreover, they investigated the effects of current density, electrochemical corrosion time, electrolyte temperature and the strength of electrolyte on the wettabilities of water, glycerin and hexadecane. Sun et al. ${ }^{[215]}$ successfully fabricated superhydrophobic and superoleophobic surfaces on titanium alloy substrates through electrochemical anodization and fluorosilane modification. The contact angles between water, glycerin and hexadecane with the prepared titanium alloy surfaces were $166.4^{\circ} \pm 1.8^{\circ}, 158.4^{\circ} \pm 2.1^{\circ}$ and $152.5^{\circ} \pm 1.9^{\circ}$ respectively, and the rolling angles of the same were all less than $10^{\circ}$. In order to obtain the best superhydrophobicity and superoleophobicity, the relationship between reaction time and surface wettability was further analyzed.

\section{(3) Chemical etching/deposition}

Yang et al. ${ }^{[252]}$ etched the aluminum surface with hydrochloric acid, and then treated the surface with hydrothermal method to obtain micro-nanoscale composite structures. The aluminum surface with the re-entrant structures was obtained by varying etching conditions. The surface exhibited superoleophobicity after modification with fluorosilane. Lim et al ${ }^{[253]}$ first polished the surface of aluminum, and etched the surface with hydrochloric acid to achieve micro-nanoscale structures. Results showed that the surface of aluminum displayed superhydrophobicity to diiodomethane and hexadecane by applying a low-surface-energy material to the surface. Zhao et al. ${ }^{[254]}$ prepared micro-nanoscale array rod patterns on copper surface by immersing copper in a mixture of sodium hydroxide and ammonium persulfate, and performed surface energy modification using a low surface energy material to generate superoleophobicity. Ou et al. ${ }^{[255]}$ prepared the superoleophobic surfaces having a micro-nanoscale structure on the copper substrates by acid and alkali etching. 


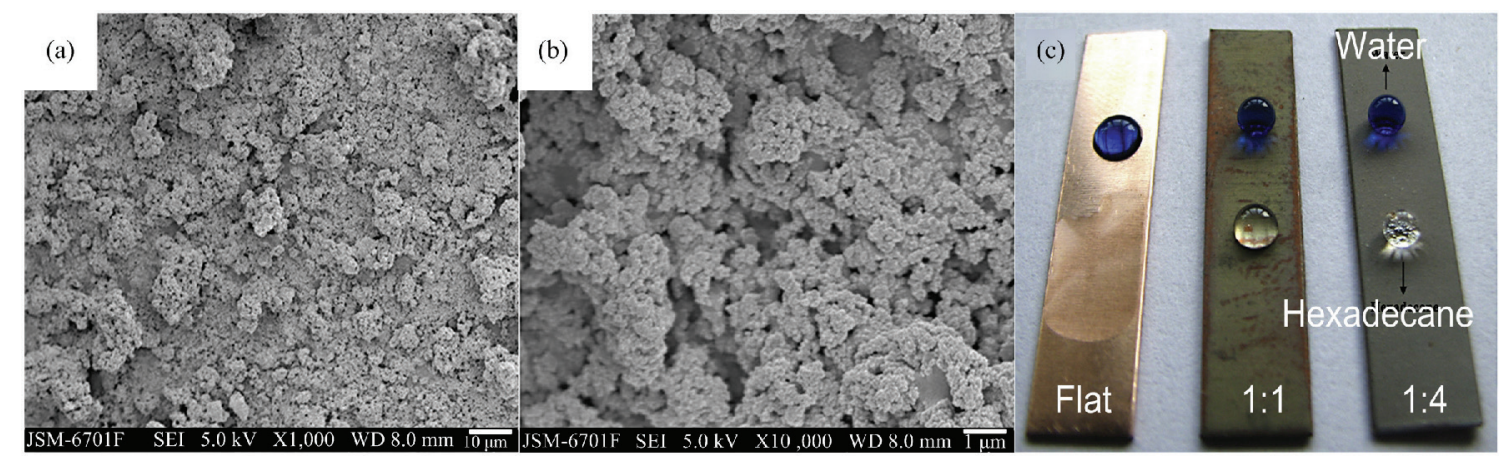

Fig. 13 Superoleophobic copper surface obtained by spray coating. (a) and (b) SEM images of the coating containing fluorinated silica and fluorinated resin with a ratio of 1:4; (c) optical images of water and hexadecane droplets sit on the original, superhydrophobic, and superoleophobic surfaces of copper ${ }^{[256]}$ (Copyright 2014 Elsevier).
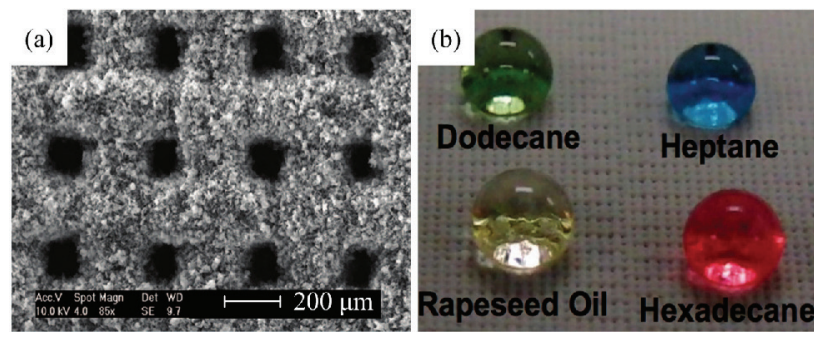

Fig. 14 Superoleophobic stainless steel mesh surface prepared by electrospinning. (a) SEM image of a polymethyl methacrylate bonded to the stainless steel mesh; (b) different oil droplets on its surface $^{[258]}$ (Copyright 2012 Wiley-VCH).

\section{(4) Spraying method}

Ge et al. ${ }^{[256]}$ sprayed synthetic silicon fluoride and fluoropolymer onto a copper substrate, and obtained different microstructures and wettabilities by changing ratios. When the ratio of silicon fluoride and fluoropolymer was $1: 1$, the surface had insignificant micronanoscale structures, exhibiting superhydrophobic and oleophobic properties. However, a large number of microconvex and granular nanoscale structures were generated on the surface by setting this ratio to $1: 4$, showing superhydrophobic and superoleophobic properties (Fig. 13). Results showed that the surface also exhibited an enhanced corrosion resistance. Tang et al. ${ }^{[257]}$ prepared wear-resistant, superhydrophobic and superoleophobic coatings by applying a mixture of polyurethane (PU)/molybdenum disulfide $\left(\mathrm{MoS}_{2}\right)$ onto a variety of substrates including copper, glass, paper, stainless steel, cloth and copper mesh. The contact angle of water with the PU/55.6\% $\mathrm{MoS}_{2}$ coating featured with mastoid structures was $157^{\circ}$, resulting in superhydrophobicity on the surface. Both superhydrophobicity and superoleophobicity occurred when the coating was modified by a chemical method. Results also indicated that the $\mathrm{PU} / 55.6 \% \mathrm{MoS}_{2}$ coating had good wear and abrasion resistance.

\section{(5) Electrospinning}

Tuteja et al.$^{[258]}$ combined polymethyl methacrylate onto stainless steel mesh by electrospinning to form a double-scale re-entrant structure (Fig. 14a). The surface exhibited superoleophobicity with the n-heptane contact angle of $155^{\circ}$ (Fig. 14b). On the double-scale re-entrant surface, the reduction in solid-liquid contact area directly resulted in an ultra-low contact angle hysteresis. In fact, they examined the surface near the three-phase contact line, and found the solid-liquid contact area was reduced due to the trapped air in the micro-nanoscale structures. Based on the extremely low contact angle hysteresis, n-heptane droplets could easily slide down and bounce off the surface. In further research work, Tuteja et al. ${ }^{[259]}$ fabricated a superhydrophobic and superoleophobic surface on stainless steel mesh by electrospinning using a mixture of fluorinated polyhedral oligomeric silsesquioxane and PDMS. The contact angles of almost all liquids including organic and inorganic concentrated acids, alkali solvents with the surface are greater than $150^{\circ}$, easily rolling and bouncing off the surface. The electrospun coating remained unchanged even after prolonged exposure to various concentrated and concentrated bases.

\subsection{Underwater superoleophobic metallic surfaces}

In the preceding section, we have summarized the progress in biomimetic superoleophobic metallic surfaces in air. Recently, inspired by fish scales, underwater 

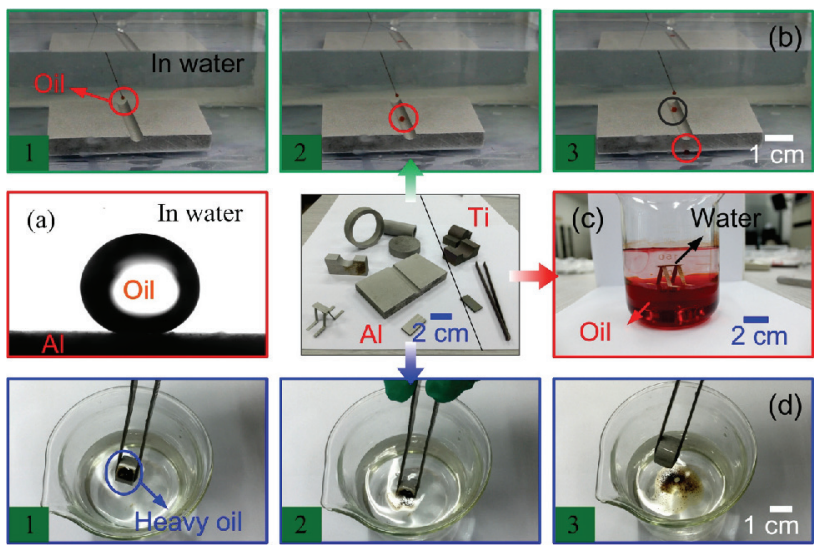

Fig. 15 Underwater superoleophobic surfaces obtained by high-speed wire electrical discharge machining. (a) Oil contact angle in water to the fabricated aluminum alloy surface; (b) underwater oil droplet guidance; (c) underwater anti-oil strider; (d) self-cleaning anti-oil ability of surface ${ }^{[263]}$ (Copyright 2017 Springer).

superoleophobic surfaces have attracted a great deal of attention due to their broad application prospects in the fields of oil droplet manipulation, anti-biological adhesion, oil-water separation and self-cleaning ${ }^{[12-14]}$. It is well-known that the hydrophilic chemical composition and micro-nano structure are the key to the preparation of underwater superoleophobic surfaces ${ }^{[17,27,34,46,60,121,162,164]}$. This part will focus on the recent developments in biomimetic superoleophobic metallic surfaces in the water environment.

\section{(1) Femto/nanosecond laser processing}

Yong et al. ${ }^{[260]}$ used the femtosecond laser to ablate the titanium surface to form micro-nanoscale structures. The structured titanium surface demonstrated superhydrophilic behavior with a high contact angle and low rolling angle of petroleum ether, hexadecane, diesel, liquid paraffin, crude oil, and chloroform in an aqueous environment, showing underwater superoleophobicity. However, under dark conditions, superhydrophobicity and underwater superoleophilicity were obtained, and the surface was restored to underwater superoleophobicity following ultraviolet (UV) irradiation. Ye et al.$^{[261]}$ used the femtosecond laser to drill the titanium foil to obtain an array microporous surface with underwater superoleophobic property. Separation of eight typical oil-water mixtures could be realized by using a simple filter device without any modification, with an efficiency of over $99 \%$. After 40 separation cycles and the application of corrosive medium, the surface still had high separation efficiency. Our group ${ }^{[262]}$ reported a simple method for commercially fabricating mechanically durable surfaces with underwater superoleophobic behavior via the nanosecond laser on common engineering metals. The unique features including underwater oil-repellent property, possibility of commercial fabrication and mechanical durability indicated potential utilization of the laser-ablated stainless steel wire mesh to remove oil from water.

\section{(2) Electrical discharge machining method}

Our group ${ }^{[263]}$ has recently used a method of high-speed wire electrical discharge machining to effectively construct curved surfaces of two- and three-dimensional shapes having underwater superoleophobicity on light alloys. Extreme underwater superoleophobicity was observed on the structured surfaces immersed in ethanol representing a high oil contact angle. In addition, a proof of concept was conducted in the applications, such as underwater oil droplet guidance, underwater anti-oil strider and self-cleaning anti-oil ability of surface (Fig. 15). In further research, our group $^{[264]}$ reported a two-step method to fabricate underwater superoleophobic surface on an aluminum alloy inspired by fish scales: high-speed wire electrical discharge machining and boiling water treatment. The micro-nanoscale structures and hydroxyl groups were observed on the aluminum alloy surface and the fabricated surface were capable of preventing contact with oil droplets when immersed into water. Furthermore, the tribological properties of the aluminum alloy surfaces with underwater superoleophobic property in water were studied, and results showed a reduced friction coefficient as compared to the polished aluminum alloy surface, showing a good underwater tribological performance.

\section{(3) Electrochemical etching/deposition/anodization}

Wang et al. ${ }^{[265]}$ successfully prepared the surface of underwater superoleophobic titanium alloy by electrochemical etching technology. The prepared titanium alloy surface had good underwater superoleophobic performance. The contact angle and sliding angle of methylene chloride in aqueous environment were $158.9^{\circ}$ $\pm 1.7^{\circ}$ and $6.4^{\circ} \pm 1.4^{\circ}$, respectively. Besides, the effects 
of corrosion time on surface wettability was studied, and the mechanism of the micro-nanoscale structure formed on the titanium alloy surface was carefully analyzed. Hou et al. ${ }^{[266]}$ prepared a nickel-coated underwater superoleophobic stainless steel mesh by electrodeposition from a deep eutectic solvent, a mixture of choline chloride and ethylene glycol. It was found that the nickel nanoparticles were uniformly distributed on the stainless steel mesh, and the resulting pore size were capable of changing with the deposition time and the applied current density, exhibiting superhydrophilicity and underwater superoleophobicity with low adhesion to oil. The modified stainless steel mesh could be used to separate oil from water, including viscous oils like crude oil and silicone oil. Moreover, separation of various oil-in-water emulsions could be achieved by using the stainless steel mesh with a small pore size. Zhou et al. ${ }^{[226]}$ prepared $\mathrm{CuWO}_{4} @ \mathrm{Cu}_{2} \mathrm{O}$ film on a copper mesh surface by electrochemical anodization. The surface had cauliflower-like structures, exhibiting superhydrophilicity and underwater superoleophobicity. Results also indicated that the treated copper mesh demonstrated high efficiency in separation of oil from water.

\section{(4) Chemical etching/deposition}

Ma et al. ${ }^{[267]}$ first polished X100 pipeline steel and then etched the surface with $\mathrm{HCl}$ solution. The microstructures generated by corrosion plus the inorganic coating with high surface energy obtained during the etching process induced a sharp transition of the X100 pipeline steel from underwater oleophilic to oleophobic state. By varying the surface morphology, the X100 pipeline steel displayed underwater superoleophobic property, resulting in an oil contact angle of $163^{\circ}$ in aqueous environment. Nishimoto et al ${ }^{[268]}$ prepared a rough titanium dioxide $\left(\mathrm{TiO}_{2}\right)$ surface by acid treatment of titanium plate and titanium mesh. After UV light irradiation, the surfaces were superhydrophilic and underwater superoleophobic. Results showed that the rough titanium mesh also had efficient oil/water separation performance. Li et al. ${ }^{[269]}$ treated a stainless steel mesh by coating it with a nanoflake honeycomb network through $\mathrm{NiOOH}$ seeding for growth on the substrate in the process of chemical bath deposition. This obtained stainless steel mesh exhibited excellent superhydrophilic

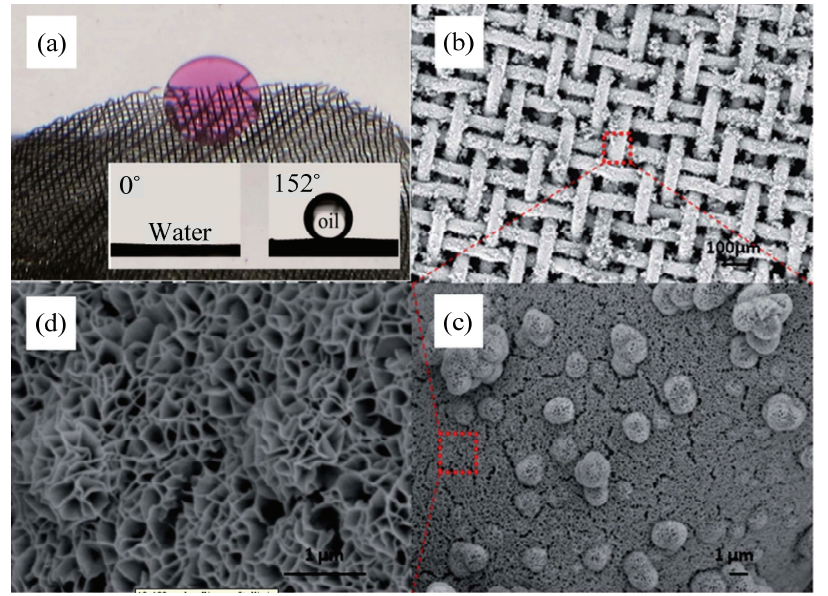

Fig. 16 Underwater superoleophobic stainless steel mesh obtained by chemical deposition. (a) Photograph of the oil droplet on stainless steel mesh in water environment; (b)-(d) SEM images of underwater superoleophobic stainless steel mesh ${ }^{[269]}$ (Copyright 2015 RSC).

and underwater superoleophobic properties. The contact angle of the water droplet in air was $0^{\circ}$, the contact angle of the oil droplet in water was $152^{\circ}$, and the $\mathrm{NiOOH}$ nanoflake honeycomb structures were produced on the stainless steel mesh surface (Fig. 16).

\section{(5) Spraying method}

Li et al. ${ }^{[270]}$ sprayed the mixture of palygorskite and polyurethane onto the surface of copper mesh to form the single fiber structures with the width of about $100 \mathrm{~nm}$ on the surface, and the treated copper mesh presented underwater superoleophobicity. The effectiveness of oil/water separation of the surface was studied by gravity driving device, and the obtained copper mesh showed an efficiency of $99.6 \%$ to remove kerosene from water. Gunatilake et al. ${ }^{[271]}$ sprayed a stainless steel mesh with hydrothermally synthesized titanium dioxide nanofibers. The contact angle of water with the treated stainless steel mesh was $2^{\circ}$, the contact angle of oil in aqueous environment with the treated surface was $162^{\circ}$, and the oil/water separation experiment was carried out based on this property.

\subsection{Slippery liquid-infused metallic surfaces}

(1) Femtosecond laser processing

Doll et al. ${ }^{[272]}$ used femtosecond laser to construct several different structures on the surface of medical titanium alloy, and then injected five different perfluo- 
ropolyurethane lubricants onto the structured surfaces. It was found that the convex structures were combined with medium viscosity lubricants (143 AZ and GPL 104) to obtain slippery liquid-infused metallic surfaces with low contact angle hysteresis. Experimental results showed that such surfaces could inhibit bacterial adhesion, and still exhibited strong antibacterial and slippery properties after being exposed to air for a long time.

\section{(2) Electrochemical anodization}

Wang et al. ${ }^{[273]}$ prepared slippery liquid-infused metallic surfaces by means of electrochemical anodization. In the experiment, the polished aluminum was employed to be working electrode, and stainless steel as the reversible electrode. A voltage $(80 \mathrm{~V})$ was applied between both electrodes, and the process of anodic oxidation was set at $30 \mathrm{~s}, 60 \mathrm{~s}$ and $120 \mathrm{~s}$ respectively. The aluminum samples were modified with fluorosilane after anodizing, and then injected into lubricant to obtain the slippery property. Results showed that the prepared slippery liquid-infused surfaces showed excellent inhi- bitory properties against anaerobic bacteria either statically and dynamically.

\section{(3) Chemical etching}

Wang et al. ${ }^{[274]}$ created a superhydrophobic coating by applying acid and hydrogen peroxide to etch a steel substrate, and then injected FC-70 into the rough structure to obtain a slippery liquid-infused porous surface. The fabricated surface is capable of repelling coffee, water, kerosene and even hexane, exhibiting excellent lyophobic behavior. It was observed that the fluidity of different liquids on the treated surface and the kinematic viscosity were inversely related (Fig. 17). Yang et al. ${ }^{[275]}$ reported a simple method to design a slippery liquidinfused porous surface. $\mathrm{HCl}$ etching and boiling water treatments were employed on the aluminum substrate to construct surface microstructures followed by injecting a fluorinated lubricant into the microstructures. The treated surface showed efficient liquid repellency to water, diiodomethane, hexadecane, dodecane and ethanol. Gao et al. ${ }^{[276]}$ etched the steel surface with the sulfuric
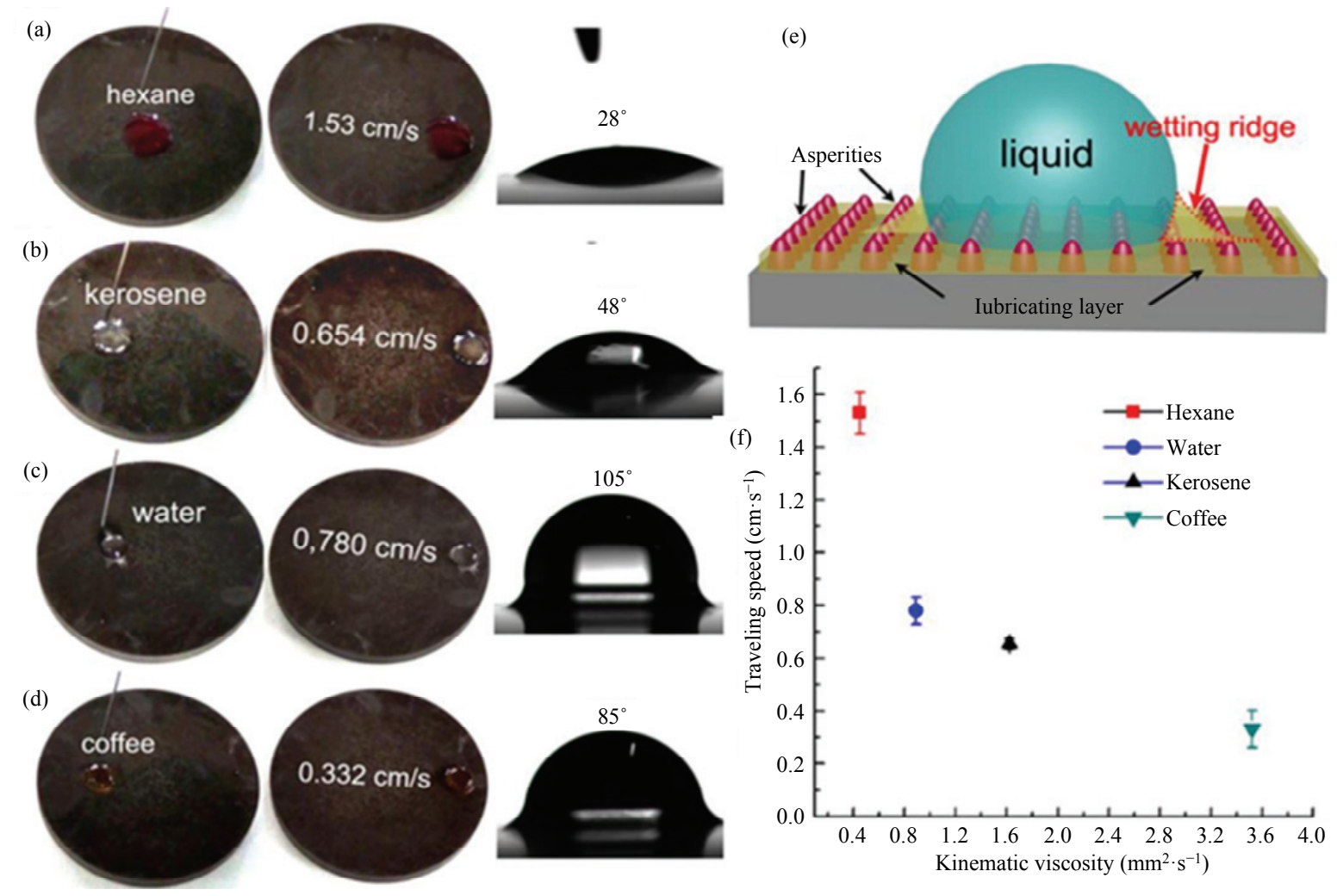

Fig. 17 Slippery liquid-infused porous steel surface obtained after chemical etching. (a-d) A $50 \mu \mathrm{L}$ droplet and the contact angles of hexane, kerosene, water and coffee with slippery liquid-infused porous surface; (e) schematic of structure of the slippery surface; (f) the relation between the kinematic viscosity and traveling speed ${ }^{[274]}$ (Copyright 2016 Elsevier). 
acid and hydrogen peroxide solution, and the surface was superhydrophobic after the fluorosilane modification. On this basis, a slippery liquid-infused porous surface was obtained after injecting perfluoropolyether into the surface. The contact angle of the water droplet with the surface was $115.6^{\circ}$, and the rolling angle was $2.27^{\circ}$.

In addition to the above preparation methods, sol-gel method, layer-by-layer self-assembly method and dip-coating method are also employed to obtain the superlyophobic property for metallic materials. Lu et $a l .{ }^{[277]}$ used sol-gel method to achieve superlyophobicity by immersing the aluminum surface into a mixture of zinc nitrate and hexamethylenetetramine. When the molar ratio between zinc nitrate and hexamethylenetetramine was $1: 1$, the surface exhibited superhydrophobicity with a water contact angle of $154.8^{\circ}$ and a contact angle hysteresis of $3^{\circ}$. Hou et al. ${ }^{[278]}$ employed layerby-layer self-assembly method to obtain an underwater superoleophobic stainless steel mesh realizing the separation of different oil/water mixtures. Jo et al. ${ }^{[279]}$ attached titanium dioxide nanoparticles to a stainless steel mesh by using dip-coating method to obtain a superhydrophilic and underwater superoleophobic surface after treated with acid and titanium dioxide, providing a treated surface to separate oil from water.

To sum up, the ever-growing demand encourages researchers to develop a number of methods to fabricate superlyophobic metallic surfaces. Some of the preparation methods have a quite mature processing mechanism and have been widely applied, achieving economic and social benefits. In general, researchers have been improving the methods for preparing superlyophobic metallic surfaces aiming to achieve high efficiency, environmental protection, low cost and suitability for industrialization.

\section{Applications of biomimetic superlyophobic metallic surfaces}

The preparation technology and applications of biomimetic superlyophobic metallic surfaces have attracted extensive attention. Furthermore, researchers have continued their investigation into more attractive applications based on the nature of superlyophobic surfaces against liquid wetting. In recent years, biomimetic superlyophobic metallic surfaces have been widely used for various applications including self-cleaning, antiicing, corrosion resistance, and drag reduction. The following is a brief introduction to several potential applications.

\subsection{Self-cleaning}

Although the lotus grows in the mud all year round, no mud can cling to the surface of its leaves. This feature results from its superhydrophobic surface that has low adhesion property. Specifically, water droplets roll off immediately upon contact with the surface, and the rolling droplets take away the attached dust particles. This property is called self-cleaning performance ("Lotus Effect"). Jiang et al. ${ }^{[6]}$ conducted an experimental investigation into the lotus leaf surface and found that the presence of micro-nanoscale structures and stratum corneum wax crystals is critical to the formation of superhydrophobicity.

Latthe et al. ${ }^{[280]}$ prepared the superhydrophobic steel surface by creating rough structure and lowering its surface energy. The water droplet was spherical on the surface with a contact angle of $164^{\circ}$. As the water droplet slid off the surface at an angle of $9^{\circ}$, dust particles were immediately picked up and removed under the action of water droplet rolling, demonstrating a self-cleaning effect. Our group ${ }^{[238]}$ reported a laser ablated aluminum alloy surface with superhydrophobicity, and studied the self-cleaning property of the flat and superhydrophobic aluminum alloy surfaces. The iron powders could not be removed when water droplets were released onto the flat surface (Figs. 18a-18d). However, they were taken away following releasing water droplets onto the superhydrophobic surface, displaying a good self-cleaning performance (Figs. 18e-18h).

Liu et al. ${ }^{[281]}$ proposed a simple method to prepare gel films on metallic substrates. The thickness of the gel film on the surface of the matrix was about $30 \mathrm{~nm}$. After the injection of lubricating oil, the droplets could roll off the surface easily due to its slippery performance. In addition, the droplets could remove dust particles away when the surface was slightly tilted, showing a good self-cleaning property.

\subsection{Anti-icing}

Icing often occurs in daily life, leading to wet roads, 

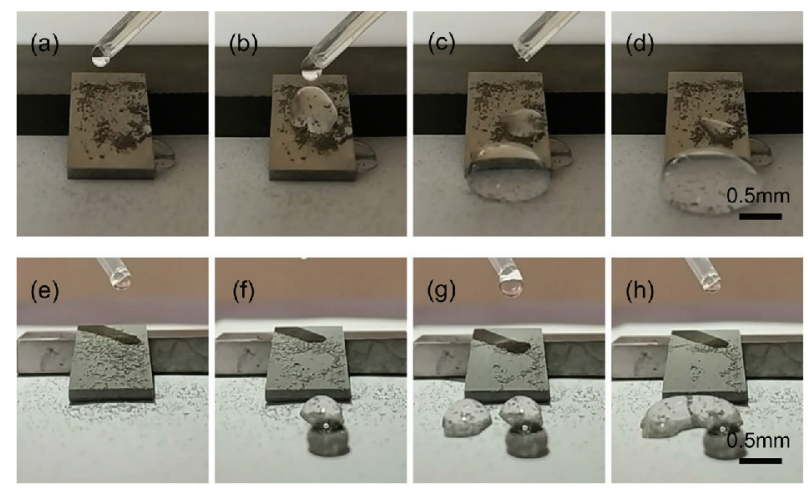

Fig. 18 Experimental study on the self-cleaning property of the $(\mathrm{a}-\mathrm{d})$ flat and $(\mathrm{e}-\mathrm{h})$ superhydrophobic aluminum alloy surfac$\mathrm{es}^{[238]}$ (Copyright 2019 Elsevier).

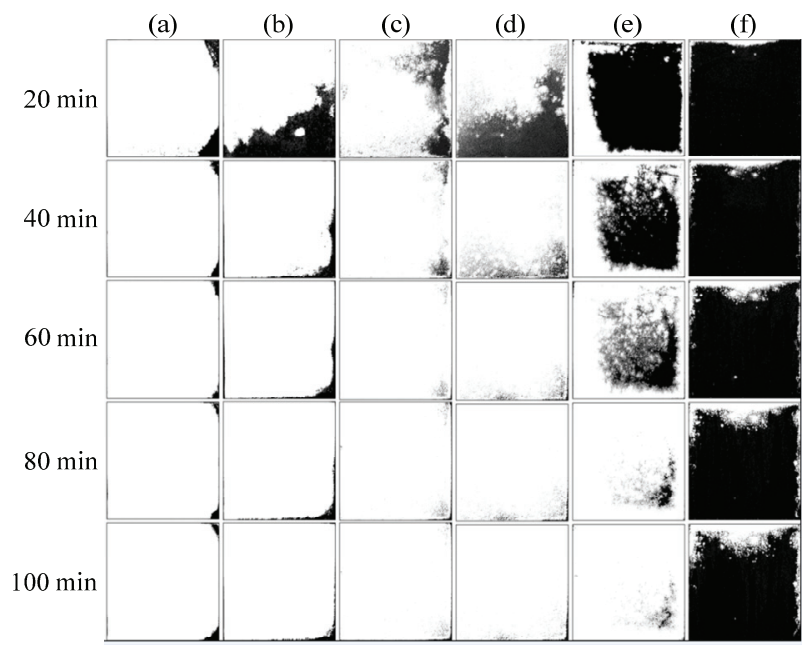

Fig. 19 Images of time-lapse threshold of frost formation (frost-covered areas displayed in white) on several aluminium surfaces. (a) Smooth aluminum surface; (b) modified (low surface energy) smooth aluminum surface; (c) infused (perfluorinated lubricants) smooth aluminum surface; (d) modified and infused smooth aluminum surface; (e) modified polypyrrole porous coating surface; (f) slippery liquid-infused porous surface. $\sim 99 \%$ of all control surfaces excluding the lubricant-infused polypyrrole coating are coated with frost after 100 minutes of freezing, and frost coverage was controlled only at $20 \%$ of the area ${ }^{[52]}$ (Copyright 2012 ACS).

attenuated signals, power outages of electronic products, and metal tube bursts. The most serious problem icing causes is that an aircraft engine may suddenly turn off, posing a serious threat to human life. Compared to conventional de-icing methods, the superlyophobic surfaces provide a relatively simple and effective strategy. Since the superlyophobic surfaces have a low rolling or sliding angle, the amount of water adhesion on the surface is reduced, and the generation of ice crystals can be delayed. The adhesion of ice crystals to the surface can also be reduced to some extent.

Boinovich et al. ${ }^{[282]}$ treated the surface by chemical etching on a stainless steel surface and then grafted a layer of siloxane to obtain excellent icing resistance. This coating surface had strong mechanical properties and maintained a high water contact angle after repeated ice-icing tests. The fundamental of the good hydrophobicity was due to the presence of the porous structures and the two-dimensional polysiloxane structures on the surface. Outdoor experiments showed that even in low-humidity environments, this low-surface energy coating surface could effectively prevent ice from adhering to the surface, exhibiting excellent anti-icing property.

Aizenberg et al. ${ }^{[52]}$ used electrochemical method to deposit polypyrrole porous coating on the surface of aluminum alloy. The injection of perfluoroalkyl ether resulted in slippery liquid-infused porous surface. Icing performances of various aluminium surfaces at different time conditions (Fig. 19) were compared. The icy area of the slippery liquid-infused porous surface was still small after $100 \mathrm{~min}$, exhibiting excellent delayed icing performance, while the ice adhesion was reduced by one/two orders of magnitude. Zhang et al. ${ }^{[61]}$ prepared two films on AZ31 magnesium alloy, the dense bottom film was used as an anti-corrosion layer, and the porous top film was injected a lubricant, and the obtained slippery liquid-infused porous surface had a small sliding angle to water. Moreover, the slippery surface provided long-lasting anti-icing property for magnesium alloy substrate, significantly better than superhydrophobic film.

\subsection{Corrosion resistance}

As a matter of fact, many surfaces are gradually deteriorated by corrosion in the actual environment, especially in the industrial field where metals are widely used. Research shows that the annual corrosion-related cost accounts for about 3\% of the world's GDP. Although paints and chromium-containing compounds are used as anti-corrosion coatings, their harmful impacts on human health and the environment discourage the widespread use of materials in everyday life and industry. Indeed, superhydrophobic coatings are an effective method to solve corrosion problems. Immersion of 


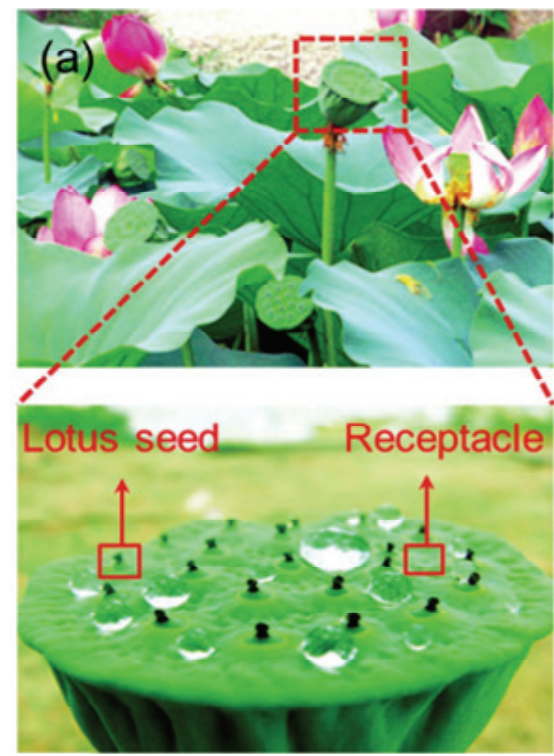

(e)

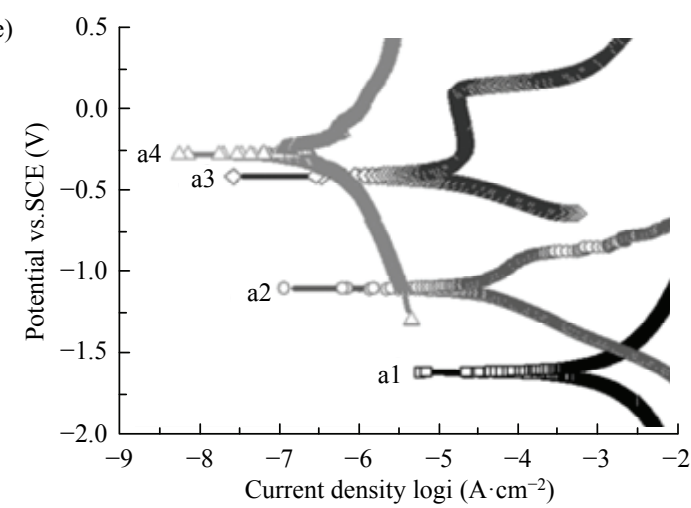

(b)
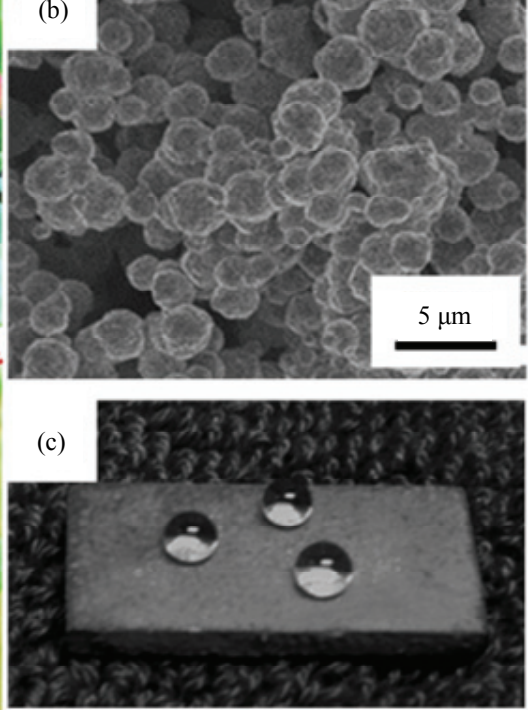

(f)

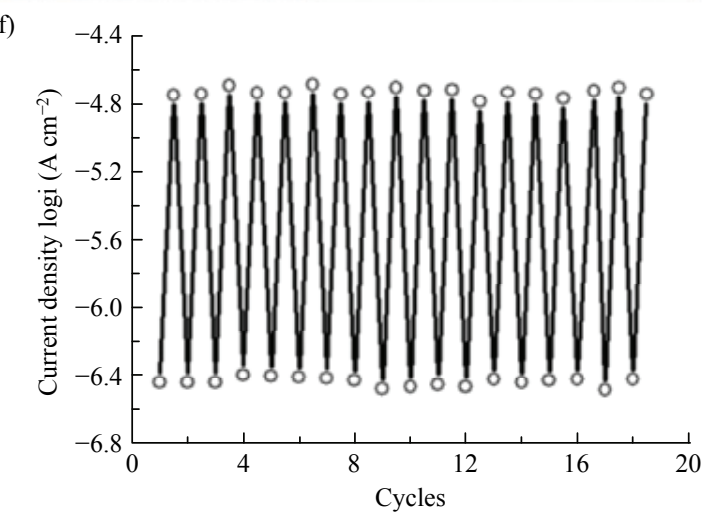

Fig. 20 Corrosion resistance of the superhydrophobic seedpod. (a) Digital photos of the seedpod and water droplets on its surface; (b) and (c) SEM images of a sphere-sea-like loose network on $\mathrm{Cu}$-thiolate treated $\mathrm{TiO}_{2} / \mathrm{AZ} 91 \mathrm{D}$ and water droplets on the surface; (d) reversible wettability transition on the treated AZ91D between superhydrophobicity and superhydrophilicity; (e) Tafel polarization curves of flat AZ91D (a1), $\mathrm{TiO}_{2} / \mathrm{AZ91D}(\mathrm{a} 2), \mathrm{Cu} / \mathrm{TiO}_{2} / \mathrm{AZ91D}$ (a3) and superhydrophobic AZ91D (a4); (f) corrosion current density obtained after each conversion cycle ${ }^{[283]}$ (Copyright 2017 Wiley-VCH).

superhydrophobic surfaces in a corrosive solution can entrap air between the rough structure and the liquid forming a natural barrier, which is capable of preventing the substrate coming into contact with the corrosive ions, thereby achieving a corrosion resistance effect.

Liu et al. ${ }^{[283]}$ reported the superhydrophobicity of a lotus seedpod (Fig. 20a) and produced a protective coating on the AZ91D magnesium alloy surface, which had a strong synergistic effect of superhydrophobicity (Fig. 20c). In the experiment, in situ hydrothermal synthesis technique was employed to paint AZ91D with titanium dioxide film, and then a superhydrophobic layer was formed on the substrate by the sonication assisted electroless plating and the self-assembled n-dodecanethiol compact monolayer (Fig. 20b). The superhydrophobicity effectively prevented direct contact between corrosive ions and the substrate (Fig. 20e). It was worth noting that it was easy to control two extreme wetting behaviors and corrosion resistance by removing the hydrophobic substance at high temperature of $350{ }^{\circ} \mathrm{C}$ and achieving modification at room temperature (Figs. 20d and 20f).

Zhang et al. ${ }^{[60]}$ successfully obtained an underwater superoleophobic coating by solution-casting method using MPS (methacryloxy propyl trimethoxy silane)- $\mathrm{SiO}_{2} / \mathrm{PNIPAM}$ (N-isopropylacrylamide) mixed nanoparticles and epoxy resin. Epoxy resin acted as an intermediate layer between the mixed nanoparticles and the matrix, improving the robustness and corrosion resistance of the coating. The obtained coating had 
(a)

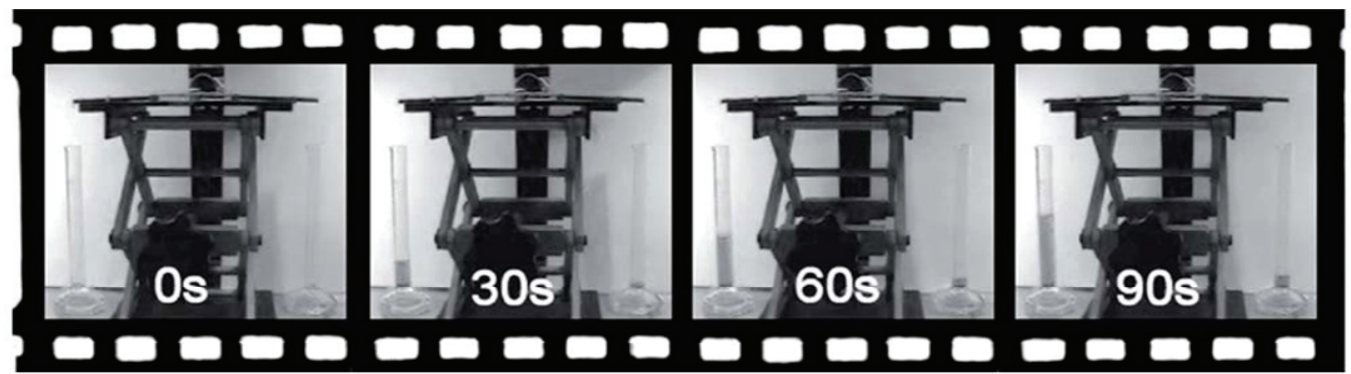

(b)

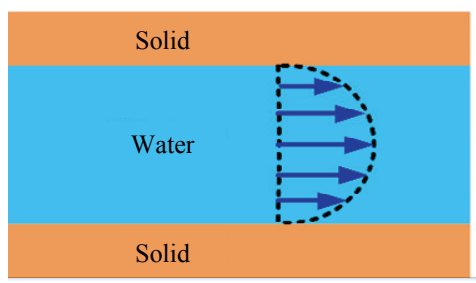

(c)

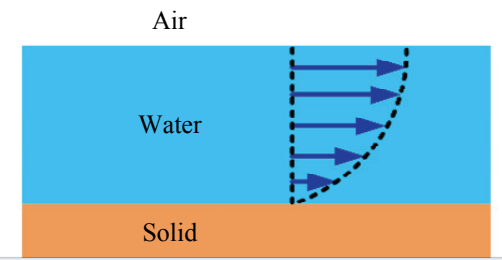

(d)

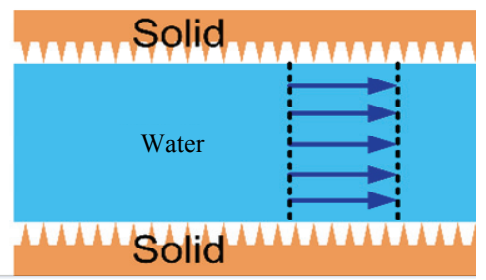

Fig. 21 Experimental study on drag reduction performance of superhydrophobic surface and cross-section of channel laminar flow under different boundary conditions. (a) Comparison of superhydrophobic and untreated tubes, the left tube is superhydrophobic; (b) no slip water-solid interface; (c) water-air interface; (d) water-air-solid composite interface ${ }^{[67]}$ (Copyright 2009 ACS).

excellent underwater superoleophobicity and still exhibited high stability in an acid-base environment. Besides, due to the presence of high density PNIPAM polymers, the coating was resistant to bacterial adhesion, thereby reducing microbial corrosion of the coating.

Wang et al. ${ }^{[284]}$ made a rough aluminum oxide film on the aluminum foil surface by electrochemical anodization. Then the fluorination of the rough layer and infiltration with lubricant resulted in slippery liquid infused porous surfaces. The prepared slippery surface could not only effectively reduce the adhesion of heat-resistant anaerobic bacteria, but also inhibit the corrosion of the substrate by corrosive media. Tuo et $a l .{ }^{[285]}$ prepared the flower-like microstructures on the aluminum foil by chemical etching and hydrothermal reaction. After modification with fluorosilane, the surface became superhydrophobic. Then the slippery liquid infused porous surface was achieved by injecting a lubricant into the surface. The sliding angle of the water droplets with the slippery surface was $3^{\circ}$. Furthermore, in terms of the corrosion current density, the slippery surface showed about two orders of magnitude lower as compared to the untreated and superhydrophobic aluminum foil surfaces. The impedance spectrum illustrated that the impedance semicircle diameter of the slippery surface was about $200 \mathrm{k} \Omega \cdot \mathrm{cm}^{2}$, indicating that the prepared slippery surface had excellent corrosion resistance.

\subsection{Drag reduction}

When an object moves, the surrounding medium will have a certain frictional resistance. For example, the resistance generated by a flowing liquid in oil pipelines is almost all frictional resistance. The frictional resistances of the submarine and torpedo in the water account for about $80 \%$ of the total resistance, even if the vessel sailing on the water and the aircraft flying in the air, the proportions are also up to $50 \%$. Therefore, it is of great significance to reduce the frictional resistance as much as possible for saving energy and increasing traveling speed. In addition, with the rapid development of Micro-Electro-Mechanical System (MEMS), the internal structures of the surface are generally on the micrometer or even nanometer scale. Relatively speaking, the frictional resistance of the solid-liquid interface is also amplified, which has become a major factor restricting the development of electronic devices.

A solid-gas interface can be usually observed when superhydrophobic surfaces are immersed in an aqueous environment ${ }^{[286]}$. The flowing water is accelerated at the water-air boundary, which is known as surface $\operatorname{slip}^{[287-290]}$. Superhydrophobic surfaces are considered a better alternative to traditional bubble drag reduction methods. Shirtcliffe et al. ${ }^{[67]}$ proposed a method for 
generating uniform superhydrophobic nanobelt structures inside a circular copper tube. A drag reduction experimental study was performed on the surface, and the flow behavior of the fluid was tested using two copper tubes. In this experiment, the fluid preferentially flowed through the superhydrophobic tube, indicating that the superhydrophobic tube wall had a lower frictional resistance (Fig. 21a). Typically, a liquid on a solid surface demonstrates laminar flow, while the velocity curve in a circular tube is parabolic (Fig. 21b) and the maximum flow is at the midpoint of the channel. In that case, the frictional resistance between solid-liquid interfaces is transferred to a much lower frictional resistance between the liquid and the air (Fig. 21c). If the channel wall is superhydrophobic, a layer of air will be observed in the wall, making the friction between the liquid and the channel wall be very similar to the fluid-air interface, exhibiting a piston-like flow rate distribution (Fig. 21d).

The liquid-floating gyro rotor has the advantages of small size, low cost and high precision. In the rotor gyroscope, the rotor speed has a great influence on the detection accuracy. Zhang et al. ${ }^{[21]}$ prepared the nano-scale line pyramid structures on the ferromagnetic rotor surface by electrochemical anodization. After modification with fluorosilane, the contact angle of the rotor surface to $3 \#$ white oil could reach $156^{\circ}$, indicating superoleophobic performance. The superoleophobicity of the rotor surface could be used to reduce the resistance in flowing liquid (3\# white oil). The test results showed that in the case of normal driving, the speed of the superoleophobic rotor could reach $3200 \mathrm{rpm}$, while the speed of the untreated rotor could only reach $2860 \mathrm{rpm}$, and the rotational speed increased by about $11.9 \%$. Therefore, a rotor with superoleophobicity could increase its rotational speed to a certain extent, thereby improving the performance of the gyro system.

As was previously stated, superlyophobic metallic surfaces have provided a variety of functions and attracted a lot of attention. However, these functional surfaces encounter various harsh environmental factors (such as corrosion and wear) in practical applications, causing the surface microstructures to be severely damaged. It imparts anti-wear and corrosion properties to the superlyophobic metallic surfaces, which can im- prove the service life of the material and ensure the more significant value in practical applications.

\section{Summary and outlook}

In recent years, with the rapid development of human society, researchers have begun deeply investigating the structure and superlyophobic property of various biological surfaces in nature using advanced testing methods, and successfully replicated these structures and their corresponding functions with advanced processing equipment. In this article, we reviewed recent achievements of biomimetic superlyophobic metallic surfaces and discussed applications of biomimetic superlyophobic metallic surfaces in self-cleaning, corrosion resistance, anti-icing, and drag reduction. But even so, there are still many problems for the biomimetic superlyophobic metallic surfaces to be solved:

(1) From the perspective of matrix materials, only conventional metallic substrates were focused including aluminum, copper, stainless steel, titanium and their alloys. Methods to achieve superlyophobicity on the surface of new metallic materials, such as super steel, shock-resistant fire-resistant steel, aluminum-lithium alloy, medical alloy, shape memory alloy, metallic porous materials, hydrogen storage alloy, shock absorbing alloy, metallic glass, metal matrix composite materials, etc., become a promising area for the research of superlyophobic metallic surfaces.

(2) In terms of preparation methods, as described above, various processing techniques have been proposed to construct microstructures on superlyophobic metallic materials, on the other hand, there are some disadvantages related to these techniques. A large amount of strong acid and alkali are involved in the electrochemical etching/anodizing and chemical etching methods, and the spraying method also uses a volatile organic solvent, posing a potential hazard to operators health when commercial production is realized. What is more, an oxidizing acid solution used in the electrochemical anodizing process, a strong acid/alkali or a heavy metal salt solution employed in the electrochemical etching and chemical etching methods and an organic solvent handled during the spraying, sol-gel, and layer-by-layer self-assembly process all have a negative 
environmental impact. Moreover, the femto/picosecond laser processing and electrospinning methods are expensive and inefficient. The chemical deposition method mainly deposits a large amount of precious metals such as gold and silver on the surface of metallic materials, which significantly increases the production cost. In the spraying, electrospinning, sol-gel, layer-by-layer self-assembly and dip-coating methods, since the obtained superlyophobic coatings on the metallic materials are mainly mechanically combined, the bonding strength with the surface is low. Compared with these methods, the nanosecond laser processing and electrical discharge machining methods have the advantages of simple process, high efficiency, low cost, mechanical durability and without using acid-base solution, and are expected to be practically applied earlier.

(3) In practical applications, shortcomings such as poor material stability in the preparation process affect the wide application of the biomimetic superlyophobic metallic surface. Furthermore, the environmental conditions at which the superlyophobic metallic surface is used are usually complicated and varied, and the corrosion resistance, wear resistance and failure resistance of the materials should be considered comprehensively. Additionally, the difficulty in large-area and highefficiency manufacturing of biomimetic superlyophobic metallic surfaces is also a tough challenge faced in practical applications.

\section{Acknowledgment}

This work was supported by the China-EU H2020 International Science and Technology Cooperation Program (FabSurfWAR Nos. 2016YFE0112100 and 644971), National Key Research and Development Plan Project (No. 2018YFB1107403), Jilin Province Scientific and Technological Development Program (No. Z20190101005JH), and the "111" Project of China (No. D17017).

Open Access This article is licensed under a Creative Commons Attribution 4.0 International License, which permits use, sharing, adaptation, distribution and reproduction in any medium or format, as long as you give appropriate credit to the original author(s) and the source, provide a link to the Creative Commons licence, and indicate if changes were made.
The images or other third party material in this article are included in the article's Creative Commons licence, unless indicated otherwise in a credit line to the material. If material is not included in the article's Creative Commons licence and your intended use is not permitted by statutory regulation or exceeds the permitted use, you will need to obtain permission directly from the copyright holder.

To view a copy of this licence, visit http://creativecommons.org/licenses/by/4.0/.

\section{References}

[1] Cheng H, Sun J R, Li J Q, Ren L Q. Structure of the integumentary surface of the dung beetle Copris ochus Motschulsky and its relation to non-adherence of substrate particles. Acta Entomologica Sinica, 2002, 45, 175-181. (in Chinese)

[2] Han Z W, Niu S C, Shang C H, Liu Z N, Ren L Q. Light trapping structures in wing scales of butterfly Trogonoptera brookiana. Nanoscale, 2012, 4, 2879-2883.

[3] Ren L Q, Li X J. Functional characteristics of dragonfly wings and its bionic investigation progress. Science China-Technological Sciences, 2013, 56, 884-897.

[4] Tong J, Lu T B, Ma Y H, Wang H K, Ren L Q, Arnell R. Two-body abrasive wear of the surface of pangolin scales. Journal of Bionic Engineering, 2007, 4, 77-84.

[5] Zhou T. Research and Application on the Abrasive Wear Resistance of Bionic Enhanced Working Parts under High Impact Force, $\mathrm{PhD}$ thesis, Jilin University, Changchun, China, 2014. (in Chinese)

[6] Feng L, Li S H, Li Y S, Li H J, Zhang L J, Zhai J, Song Y L, Liu B Q, Jiang L, Zhu D B. Super-hydrophobic surfaces: From natural to artificial. Advanced Materials, 2002, 14, $1857-1860$

[7] Neinhuis C, Barthlott W. Characterization and distribution of water-repellent, self-cleaning plant surfaces. Annals of Botany, 1997, 79, 667-677.

[8] Li X M, David R, Mercedes C C. What do we need for a superhydrophobic surface? A review on the recent progress in the preparation of superhydrophobic surfaces. Chemical Society Reviews, 2007, 36, 1350-1368.

[9] Jan G, Kirill E. Recent developments in superhydrophobic surfaces and their relevance to marine fouling: A review. Biofouling, 2006, 22, 339-360.

[10] Guo Z G, Liu W M, Su B L. Superhydrophobic surfaces: From natural to biomimetic to functional. Journal of Colloid 
and Interface Science, 2011, 353, 335-355.

[11] Verho T, Bower C L, Andrew P, Franssila S. Mechanically durable superhydrophobic surfaces. Advanced Materials, 2011, 23, 673-678.

[12] Liu K S, Tian Y, Jiang L. Bio-inspired superoleophobic and smart materials: Design, fabrication, and application. Progress in Materials Science, 2013, 58, 503-564.

[13] Yong J L, Chen F, Yang Q, Huo J, Hou X. Superoleophobic surfaces. Chemical Society Reviews, 2017, 46, 4168-4213.

[14] Jiang T, Guo Z G, Liu W M. Biomimetic superoleophobic surfaces: Focusing on their fabrication and applications. Journal of Materials Chemistry A, 2015, 3, 8-14.

[15] Darmanin T, Guittard F. Superhydrophobic and superoleophobic properties in nature. Materials Today, 2015, 18, 273-285.

[16] Kota A K, Kwon G, Tuteja A. The design and applications of superomniphobic surfaces. NPG Asia Materials, 2014, 6, e109.

[17] Yong J L, Chen F, Yang Q, Jiang Z D, Hou X. A review of femtosecond-laser-induced underwater superoleophobic surfaces. Advanced Materials Interfaces, 2018, 5, 1701370.

[18] Wang W D, Timonen J V I, Andreas C, Drotlef D M, Zhang C T, Kolle S, Grinthal A, Wong T S, Hatton B, Kang S H, Kennedy S, Chi J, Blough R T, Stitti M, Mahadevan L, Aizenberg J. Multifunctional ferrofluid-infused surfaces with reconfigurable multiscale topography. Nature, 2018, 559, 77-82.

[19] Li J S, Ueda E, Paulssen D, Levkin P A. Slippery lubricantinfused surfaces: Properties and emerging applications. Advanced Functional Materials, 2018, 29, 1802317.

[20] Sun Y H, Guo Z G. Recent advances of bioinspired functional materials with specific wettability: From nature and beyond nature. Nanoscale Horizons, 2019, 4, 52-76.

[21] Howell C, Grinthal A, Sunny S, Aizenberg M, Aizenberg J. Designing liquid-infused surfaces for medical applications: A review. Advanced Materials, 2018, 30, 1802724.

[22] Ragesh P, Ganesh V A, Nair S V, Nair A S. A review on 'self-cleaning and multifunctional materials'. Journal of Materials Chemistry A, 2014, 2, 14773-14797.

[23] Nishimoto S, Bhushan B. Bioinspired self-cleaning surfaces with superhydrophobicity, superoleophobicity, and superhydrophilicity. RSC Advances, 2013, 3, 671-690.

[24] Liu K S, Jiang L. Bio-inspired self-cleaning surfaces. Annual Review of Materials Research, 2012, 42, 231-263.

[25] Shen L, Wang B L, Wang J L, Fu J H, Picart C, Ji J. A symmetric film with multifunctional anti-bacterial and self-cleaning properties. ACS Applied Materials \& Inter- faces, 2012, 4, 4476-4483.

[26] Barberoglou M, Zorba V, Stratakis E, Spanakis E, Tzanetakis $\mathrm{P}$, Anastasiadis S H, Fotakis C. Bio-inspired water repellent surfaces produced by ultrafast laser structuring of silicon. Applied Surface Science, 2009, 255, 5425-5429.

[27] Wu D, Wu S Z, Chen Q D, Zhao S, Zhang H, Jiao J, Pierso J A, Wang J N, Sun H B, Jiang L. Facile creation of hierarchical PDMS microstructures with extreme underwater superoleophobicity for anti-oil application in microfluidic channels. Lab on a Chip, 2011, 11, 3873-3879.

[28] Zhang E, Cheng Z, Lv T, Li L, Liu Y. The design of underwater superoleophobic $\mathrm{Ni} / \mathrm{NiO}$ microstructures with tunable oil adhesion. Nanoscale, 2015, 7, 19293-19299.

[29] Guo T Q, Che P D, Heng L P, Fan L Z, Jiang L. Anisotropic slippery surfaces: Electric-driven smart control of a drop's slide. Advanced Materials, 2016, 28, 6999-+.

[30] Wu X H, Chen Z. A mechanically robust transparent coating for anti-icing and self-cleaning applications. Journal of Materials Chemistry A, 2018, 6, 16043-16052.

[31] Genzer J, Efimenko K. Recent developments in superhydrophobic surfaces and the irrelevance to marine fouling: A review. Biofouling, 2006, 22, 339-360.

[32] Zhao L, Liu Q, Gao R, Wang J, Yang W L, Liu L H. One-step method for the fabrication of superhydrophobic surface on magnesium alloy and its corrosion protection, antifouling performance. Corrosion Science, 2014, 80, 177-183.

[33] Magin C M, Cooper S P, Brennan A B. Non-toxic antifouling strategies. Materials Today, 2010, 13, 36-44.

[34] Wang D H, Liu H Y, Yang J L, Zhou S X. Seawater-induced healable underwater superoleophobic antifouling coatings. ACS Applied Materials \& Interfaces, 2019, 11, 1353-1362.

[35] Zhou X, Lee Y Y, Chong K S L, He C B. Superhydrophobic and slippery liquid-infused porous surfaces formed by the self-assembly of a hybrid ABC triblock copolymer and their antifouling performance. Journal of Materials Chemistry B, 2018, 6, 440-448.

[36] Tesler A B, Kim P, Kolle S, Howell C, Ahanotu O, Aizenberg J. Extremely durable biofouling-resistant metallic surfaces based on electrodeposited nanoporous tungstite films on steel. Nature Communications, 2015, 6, 8649.

[37] Epstein A K, Wong T S, Belisle R A, Boggs E M, Aizenberg J. Liquid-infused structured surfaces with exceptional anti-biofouling performance. Proceedings of the National Academy of Sciences of the United States of America, 2012, 109, 13182-13187.

[38] Xue C H, Guo X J, Ma J Z, Jia S T. Fabrication of robustand antifouling superhydrophobic surfaces via surface-initiated 
atom transfer radical polymerization. ACS Applied Materials \& Interfaces, 2015, 7, 8251-8259.

[39] Selim M S, Shenashen M A, El-Safty S A, Higazy S A, Selim M M, Isago $\mathrm{H}$, Elmarakbi A. Recent progress in marine foul-release polymeric nanocomposite coatings. Progress in Materials Science, 2017, 87, 1-32.

[40] Tenjimbayashi M, Park J Y, Muto J, Kobayashi Y, Yoshikawa R, Monnai Y, Shiratori S. In situ formation of slippery-liquid-infused nanofibrous surface for a transparent antifouling endoscope lens. ACS Biomaterials Science \& Engineering, 2018, 4, 1871-1879.

[41] Lai Y K, Tang Y X, Gong J J, Gong D G, Chi L F, Ling C J. Transparent superhydrophobic/superhydrophilic $\mathrm{TiO}_{2}$-based coatings for self-cleaning and anti-fogging. Journal of Materials Chemistry, 2012, 22, 7420-7426.

[42] Han Z W, Feng X M, Guo Z G, Niu S C, Ren L Q. Flourishing bioinspired antifogging materials with superwettability: Progresses and challenges. Advanced Materials, 2018, 30, 1704652.

[43] Han Z W, Mu Z Z, Li B, Wang Z, Zhang J Q, Niu S C, Ren L Q. Active antifogging property of monolayer $\mathrm{SiO}_{2}$ film with bioinspired multiscale hierarchical pagoda structures. $A C S$ Nano, 2016, 10, 8591-8602.

[44] Sun Z Q, Liao T, Liu K S, Jiang L, Dou S X. Fly-eye inspired superhydrophobic anti-fogging inorganic nanostructures. Small, 2014, 10, 3001-3006.

[45] Chen Y, Zhang Y B, Shi L, Li J, Xin Y, Yang T T, Guo Z G. Transparent superhydrophobic/superhydrophilic coatings for self-cleaning and anti-fogging. Applied Physics Letters, 2012, 101, 033701.

[46] Tang L, Zeng Z X, Wang G, Shen L L, Zhu L J, Zhang Y X, Xue Q J. Study of oil dewetting ability of superhydrophilic and underwater superoleophobic surfaces from air to water for high-effective self-cleaning surface designing. ACS Applied Materials \& Interfaces, 2019, 20, 18865-18875.

[47] Guo H S, Xu T, Zhang J M, Zhao W Q, Zhang J W, Lin C G, Zhang L. A multifunctional anti-fog, antibacterial, and self-cleaning surface coating based on poly(NVP-co-MA). Chemical Engineering Journal, 2018, 351, 409-417.

[48] Cao L, Jones A K, Sikka V K, Wu J, Gao D. Anti-icing superhydrophobic coatings. Langmuir, 2009, 25, 12444-12448.

[49] Schutzius T M, Jung S, Maitra T, Graeber G, Khme M, Poulikakos D. Spontaneous droplet trampolining on rigid superhydrophobic surfaces. Nature, 2015, 527, 82-85.

[50] Mishchenko L, Hatton B, Bahadur V, Taylor J A, Krupenkin $\mathrm{T}$, Aizenberg J. Design of ice-free nanostructured surfaces based on repulsion of impacting water droplets. ACS Nano, 2010, 4, 7699-7707.

[51] Nosonovsky M, Hejazi V. Why superhydrophobic surfaces are not always icephobic. ACS Nano, 2012, 6, 8488-8491.

[52] Kim P, Wong T S, Alvarenga J, Kreder M J, AdornoMartinez W E, Aizenberg J. Liquid-infused nanostructured surfaces with extreme anti-ice and anti-frost performance. ACS Nano, 2012, 6, 6569-6577.

[53] Kreder M J, Alvarenga J, Kim P, Aizenberg J. Design of anti-icing surfaces: Smooth, textured or slippery? Nature Reviews Materials, 2016, 1, UNSP 15003.

[54] Irajizad P, Hasnain M, Farokhnia N, Sajadi S M, Ghasemi H. Magnetic slippery extreme icephobic surfaces. Nature Communications, 2016, 7, 13395.

[55] Liu Y, Li S Y, Zhang J J, Liu J A, Han Z W, Ren L Q. Corrosion inhibition of biomimetic super-hydrophobic electrodeposition coatings on copper substrate. Corrosion Science, 2015, 94, 190-196.

[56] Liu Y, Yin X M, Zhang J J, Yu S R, Han Z W, Ren L Q. A electro-deposition process for fabrication of biomimetic super-hydrophobic surface and its corrosion resistance on magnesium alloy. Electrochimica Acta, 2014, 125, 395-403.

[57] Boinovich L B, Modin E B, Sayfutdinova A R, Emelyanenko K A, Vasiliev A L, Emelyanenko A M. Combination of functional nanoengineering and nanosecond laser texturing for design of superhydrophobic aluminum alloy with exceptional mechanical and chemical properties. ACS Nano, 2017, 11, 10113-10123.

[58] Xu W J, Song J L, Sun J, Lu Y, Yu Z Y. Rapid fabrication of large-area, corrosion-resistant superhydrophobic $\mathrm{Mg}$ alloy surfaces. ACS Applied Materials \& Interfaces, 2011, 3, 4404-4414.

[59] Wang N, Xiong D S, Deng Y L, Shi Y, Wang K. Mechanically robust superhydrophobic steel surface with anti-icing, UV-durability, and corrosion resistance properties. $A C S$ Applied Materials \& Interfaces, 2015, 7, 6260-6272.

[60] Su M, Liu Y, Zhang Y H, Wang Z G, Li Y L, He P X. Robust and underwater superoleophobic coating with excellent corrosion and biofouling resistance in harsh environments. Applied Surface Science, 2017, 436, 152-161.

[61] Zhang J L, Gu C D, Tu J P. Robust slippery coating with superior corrosion resistance and anti-icing performance for AZ31B Mg alloy protection. ACS Applied Materials \& Interfaces, 2017, 9, 11247-11257.

[62] Xiang T F, Zhang M, Sadig H R, Li Z C, Zhang M X, Dong C D, Yang L, Chan W M, Li C. Slippery liquid-infused porous surface or corrosion protection with self-healing 
property. Chemical Engineering Journal, 2018, 345, $147-155$.

[63] Shi F, Niu J, Liu J, Liu F, Wang Z, Feng X Q, Zhang X. Towards understanding why a superhydrophobic coating is needed by water striders. Advanced Materials, 2007, 19, 2257-2261.

[64] Dong H Y, Cheng M J, Zhang Y J, Wei H, Shi F. Extraordinary drag-reducing effect of a superhydrophobic coating on a macroscopic model ship at high speed. Journal of Materials Chemistry A, 2013, 1, 5886-5891.

[65] Wu Y, Wei Q B, Cai M R, Zhou F. Friction: Interfacial friction control. Advanced Materials Interfaces, 2015, 2, 1400392.

[66] McHale G, Newton M I, Shirtcliffe N J. Immersed superhydrophobic surfaces: Gas exchange, slip and drag reduction properties. Soft Matter, 2010, 6, 714-719.

[67] Shirtcliffe N J, McHale G, Newton M I, Zhang Y. Superhydrophobic copper tubes with possible flow enhancement and drag reduction. ACS Applied Materials \& Interfaces, 2009, 1, 1316-1323.

[68] McHale G, Shirtcliffe N J, Evans C R, Newton M I. Terminal velocity and drag reduction measurements on superhydrophobic spheres. Applied Physics Letters, 2009, 94, 064104.

[69] Hemeda A A, Tafreshi H V. Liquid-infused surfaces with trapped air (LISTA) for drag force reduction. Langmuir, 2016, 32, 2955-2962.

[70] Wang Y, Zhang H F, Liu X W, Zhou Z P. Slippery liquidinfused substrates: A versatile preparation, unique antiwetting and drag-reduction effect on water. Journal of $\mathrm{Ma}$ terials Chemistry A, 2016, 4, 2524-2529.

[71] Kim G H, Lee B H, Im H, Jeon S B, Kim D, Seol M L, Hwang H, Choi Y K. Controlled anisotropic wetting of scalloped silicon nanogroove. RSC Advanced, 2016, 6, 41914-41918.

[72] Wang S L, Wang T Q, Ge P, Xue P H, Ye S S, Chen H X, Li Z B, Zhang J H, Yang B. Controlling flow behavior of water in microfluidics with a chemically patterned anisotropic wetting surface. Langmuir, 2015, 31, 4032-4039.

[73] Songok J, Tuominen M, Teisala H, Haapanen J, Makela J, Kuusipalo J, Toivakka M. Paper-based microfluidics: Fabrication technique and dynamics of capillary-driven surface flow. ACS Applied Materials \& Interfaces, 2014, 6, 20060-20066.

[74] Ghosh A, Ganguly R, Schutzius T M, Megaridis C M. Wettability patterning for high-rate, pumpless fluid transport on open, non-planar microfluidic platforms. Lab on a Chip, 2014, 14, 1538-1550.
[75] Casavant B P, Berthier E, Theberge A B, Berthier J, Montanez-Sauri S I, Bischel L L, Brakke K, Hedman C J, Bushman W, Keller N P, Beebe D J. Suspended microfluidics. Proceedings of the National Academy of Sciences of the United States of America, 2013, 110, 10111-10116.

[76] Zhao B, Moore J S, Beebe D J. Virtual electrowetting channels: Electronic liquid transport with continuous channel functionality. Science, 2001, 291, 1023-1026.

[77] Gogolides E, Ellinas K, Tserepi A. Hierarchical micro and nano structured, hydrophilic, superhydrophobic and superoleophobic surfaces incorporatedin microfluidics, microarrays and lab on chip microsystems. Microelectronic Engineering, 2015, 132, 135-155.

[78] You I, Lee T G, Nam Y S, Lee H. Fabrication of a microomnifluidic device by omniphilic/omniphobic patterning on nanostructured surfaces. ACS Nano, 2014, 8, 9016-9024.

[79] Vitale A, Quaglio M, Marasso S L, Chiodoni A, Cocuzza M, Bongiovanni R. Direct photolithography of perfluoropolyethers for solvent-resistant microfluidics. Langmuir, 2013, 29, 15711-15718.

[80] Kim T I, Suh K Y. Unidirectional wetting and spreading on stooped polymer nanohairs. Soft Matter, 2009, 5, 4131-4135.

[81] Kwon K W, Choi S S, Lee S H, Kim B, Lee S N, Park M C, Kim P, Hwang S Y, Suh K Y. Label-free, microfluidic separation and enrichment of human breast cancer cells by adhesion difference. Lab on a Chip, 2007, 7, 1461-1468.

[82] Ren H X, Chen X, Huang X J, Im M, Kim D H, Lee J H, Yoon J B, Gu N, Liu J H, Choi Y K. A conventional route to scalable morphology-controlled regular structures and their superhydrophobic/hydrophilic properties for biochips application. Lab on a Chip, 2009, 9, 2140-2144.

[83] Movafaghi S, Wang W, Metzger A, Williams D D, Williams J D, Kota A K. Tunable superomniphobic surfaces for sorting droplets by surface tension. Lab on a Chip, 2016, 16, 3204-3209.

[84] Ivanova E P, Hasan J, Webb H K, Gervinskas G, Juodkazis S, Truong V K, Wu A H, Lamb R N, Baulin V A, Watson G S, Watson J A, Mainwaring D E, Crawford R J. Bactericidal activity of black silicon. Nature Communications, 2013, 4, 2838.

[85] Huang Q, Lin L, Yang Y, Hu R, Vogler E A, Lin C. Role of trapped air in the formation of cell-and-protein micropatterns on superhydrophobic/superhydrophilic microtemplated surfaces. Biomaterials, 2012, 33, 8213-8220.

[86] Ranella A, Barberoglou M, Bakogianni S, Fotakis C, Stratakis E. Tuning cell adhesion by controlling the roughness 
and wettability of 3D micro/nano silicon structures. Acta Biomaterialia, 2010, 6, 2711-2720.

[87] Fadeeva E, Truong V K, Stiesch M, Chichkov B N, Crawford R J, Wang J, Ivanova E P. Bacterial retention on superhydrophobic titanium surfaces fabricated by femtosecond laser ablation. Langmuir, 2011, 27, 3012-3019.

[88] Stratakis E, Ranella A, Fotakis C. Biomimetic micro/nanostructured functional surfaces for microfluidic and tissue engineering applications. Biomicrofluidics, 2011, 5, 013411.

[89] McHale G, Newton M I. Liquid marbles: Topical context within soft matter and recent progress. Soft Matter, 2015, 11, 2530-2546.

[90] Ueda E, Levkin P A. Micropatterning hydrophobic liquid on a porous polymer surface for long-term selective cell-repellency. Advanced Healthcare Materials, 2013, 2, 1425-1429.

[91] Liu X J, Liang Y M, Zhou F, Liu W M. Extreme wettability and tunable adhesion: biomimicking beyond nature? Soft Matter, 2012, 8, 2070-2086.

[92] Wang M, Chen C, Ma J P, Xu J. Preparation of superhydrophobic cauliflower-like silica nanospheres with tunable water adhesion. Journal of Materials Chemistry, 2011, 21, 6962-6967.

[93] Yong J L, Chen F, Yang Q, Zhang D, Du G, Si J, Yun F, Hou $\mathrm{X}$. Femtosecond laser weaving superhydrophobic patterned PDMS surfaces with tunable adhesion. Journal of Physical Chemistry C, 2013, 117, 24907-24912.

[94] Yong J L, Yang Q, Chen F, Zhang D, Farooq U, Du G, Hou X. A simple way to achieve superhydrophobicity, controllable water adhesion, anisotropic sliding, and anisotropic wetting based on femtosecond-laser-induced line-patterned surfaces. Journal of Materials Chemistry A, 2014, 2, 5499-5507.

[95] Li J, Jing Z J, Zha F, Yang Y X, Wang Q T, Lei Z Q. Facile spray-coating process for the fabrication of tunable adhesive superhydrophobic surfaces with heterogeneous chemical compositions used for selective transportation of microdroplets with different volumes. ACS Applied Materials \& Interfaces, 2014, 6, 8868-8877.

[96] Yao X, Gao J, Song Y L, Jiang L. Superoleophobic surfaces with controllable oil adhesion and their application in oil transportation. Advanced Functional Materials, 2011, 21, 4270-4276.

[97] Yong J L, Yang Q, Chen F, Bian H, Du G Q, Farooq U, Hou $X$. Reversible underwater lossless oil droplet transportation. Advanced Materials Interfaces, 2015, 2, 1400388.

[98] Cheng Z J, Liu H W, Lai H, Du Y, Fu K W, Li C, Yu J X,
Zhang N Q, Sun K N. Regulating underwater oil adhesion on superoleophobic copper films through assembling n-alkanoic acids. ACS Applied Materials \& Interfaces, 2015, 7, 20410-20417.

[99] Li G Q, Zhang Z, Wu P C, Wu S Z, Hu Y L, Zhu W L, Li J W, Wu D, Li X H, Chu J R. One-step facile fabrication of controllable microcone and micromolar silicon arrays with tunable wettability by liquid-assisted femtosecond laser irradiation. RSC Advanced, 2016, 6, 37463-37471.

[100] Su B, Wang S T, Song Y L, Jiang L. Utilizing superhydrophilic materials to manipulate oil droplets arbitrarily in water. Soft Matter, 2011, 7, 5144-5149.

[101] Guo P, Wang Z B, Heng L P, Zhang Y Q, Wang X, Jiang L. Magnetocontrollable droplet and bubble manipulation on a stable amphibious slippery gel surface. Advanced Functional Materials, 2019, 29, 1808717.

[102] Che P D, Heng L P, Jiang L. Lubricant-infused anisotropic porous surface design of reduced graphene oxide toward electrically driven smart control of conductive droplets' motion. Advanced Functional Materials, 2017, 27, 1606199.

[103] Chen C L, Weng D, Mahmood A, Chen S, Wang J D. Separation mechanism and construction of surfaces with special wettability for oil/water separation. ACS Applied Materials \& Interfaces, 2019, 11, 11006-11027.

[104] Yong J L, Huo J L, Chen F, Yang Q, Hou X. Oil/water separation based on natural materials with super-wettability: Recent advances. Physical Chemistry Chemical Physics, 2018, 20, 25140-25163.

[105] Xue Z X, Cao Y Z, Liu N, Feng L, Jiang L. Special wettable materials for oil/water separation. Journal of Materials Chemistry A, 2014, 2, 2445-2460.

[106] Wang B, Liang W X, Guo Z G, Liu W M. Biomimetic superlyophobic and super-lyophilic materials applied for oil/water separation: A new strategy beyond nature. Chemical Society Reviews, 2015, 44, 336-361.

[107] Chu Z L, Feng Y J, Seeger S. Oil/water separation with selective superantiwetting/superwetting surface materials. Angewandte Chemie International Edition, 2015, 54, 2328-2338.

[108] Han Z W, Li B, Mu Z Z, Niu S C, Zhang J Q, Ren L Q. Energy-efficient oil-water separation of biomimetic copper membrane with multiscale hierarchical dendritic structures. Small, 2017, 13, 1701121.

[109] Liu Y Q, Jiao Z Z, Zhang Y L, Liu Y, Jiang H B, Han D D, Sun H B. Kraft mesh origami for efficient oil-water separation. Langmuir, 2019, 35, 815-823.

[110] Wang S T, Song Y L, Jiang L. Microscale and nanoscale 
hierarchical structured mesh films with superhydrophobic and superoleophilic properties induced by long-chain fatty acids. Nanotechnology, 2007, 18, 015103.

[111] Liu Y, Zhang K T, Son Y, Zhang W, Spindler L M, Han Z W, Ren L Q. A smart switchable bioinspired copper foam responding to different $\mathrm{pH}$ droplets for reversible oil-water separation. Journal of Materials Chemistry A, 2017, 5, 2603-2612.

[112] Liu Y, Zhan B, Zhang K T, Kaya C, Stegmaier T, Han Z W, Ren L Q. On-demand oil/water separation of 3D Fe foam by controllable wettability. Chemical Engineering Journal, 2018, 331, 278-289.

[113] Li K, Ju J, Xue Z X, Ma J, Feng L, Gao S, Jiang L. Structured cone arrays for continuous and effective collection of micron-sized oil droplets from water. Nature Communications, 2013, 4, 2276.

[114] Ju G N, Cheng M J, Shi F. A pH-responsive smart surface for the continuous separation of oil/water/oil ternary mixtures. NPG Asia Materials, 2014, 6, e111.

[115] Zhang W B, Shi Z, Zhang F, Liu X, Jin J, Jiang L. Superhydrophobic and superoleophilic pvdf membranes for effective separation of water-in-oil emulsions with high flux. Advanced Materials, 2013, 25, 2071-2076.

[116] Gao S J, Shi Z, Zhang W B, Zhang F, Jin J. Photoinduced superwetting single-walled carbon nanotube $/ \mathrm{TiO}_{2}$ ultrathin network films for ultrafast separation of oil-in-water emulsions. ACS Nano, 2014, 8, 6344-6352.

[117] Shirtcliffe N J, McHale G, Newton M I. Learning from superhydrophobic plants: The use of hydrophilic areas on superhydrophobic surfaces for droplet control. Langmuir, 2009, 25, 14121-14128.

[118] Nakajima A. Design of hydrophobic surfaces for liquid droplet control. NPG Asia Materials, 2011, 3, 49-56.

[119] Zahner D, Abagat J, Svec F, Frechet J M, Levkin P A. A facile approach to superhydrophilic-superhydrophobic patterns in porous polymer films. Advanced Materials, 2011, 23, 3030-3034.

[120] Mertaniemi H, Jokinen V, Sainiemi L, Franssila S, Marmur A, Ikkala O, Ras R H. Superhydrophobic tracks for low-friction, guided transport of water droplets. Advanced Materials, 2011, 23, 2911-2914.

[121] Li G Q, Lu Y, Wu P C, Zhang Z, Li J W, Zhu W L, Hu Y L, Wu D, Chu J R. Fish scale inspired design of underwater superoleophobic microcone arrays by sucrose solution assisted femtosecond laser irradiation for multifunctional liquid manipulation. Journal of Materials Chemistry A, 2015, 3, 18675-18683.
[122] Glavan A C, Martinez R V, Subramaniam A B, Yoon H J, Nunes R M D, Lange H, Thuo M M, Whitesides G M. Omniphobic " $\mathrm{R}^{\mathrm{F}}$ paper" produced by silanization of paper with fluoroalkyltrichlorosilanes. Advanced Functional Materials, 2014, 24, 60-70.

[123] Wang Z B, Heng L P, Jiang L. Effect of lubricant viscosity on the self-healing properties and electrically driven sliding of droplets on anisotropic slippery surfaces. Journal of Materials Chemistry A, 2017, 6, 3414-3421.

[124] Parker A R, Lawrence C R. Water capture by a desert beetle. Nature, 2001, 414, 33-34.

[125] Zhai L, Berg M C, Cebeci F C, Kim Y, Milwid J M, Rubner M F, Cohen R E. Patterned superhydrophobic surfaces: Toward a synthetic mimic of the Namib Desert beetle. Nano Letters, 2006, 6, 1213-1217.

[126] Garrod R P, Harris L G, Schofield W C E, McGettrick J, Ward L J, Teare D O H, Badyal J P S. Mimicking a Stenocara beetle's back for microcondensation using plasmachemical patterned superhydrophobic-superhydrophilic surfaces. Langmuir, 2007, 23, 689-693.

[127] Park K C, Kim P, Grinthal A, He N, Fox D, Weaver J C, Aizenberg J. Condensation on slippery asymmetric bumps. Nature, 2016, 531, 78-82.

[128] Luo H, Lu Y, Yin S H, Huang S, Song J L, Chen F Z, Chen F J, Carmalt C J, Parkin I P. Robust platform for water harvesting and directional transport. Journal of Materials Chemistry A, 2018, 6, 5635-5643.

[129] De Angelis F, Gentile F, Mecarini F, Das G, Moretti M, Candeloro P, Coluccio M L, Cojoc G, Accardo A, Liberale C, Zaccaria R P, Perozziello G, Tirinato L, Toma A, Cuda G, Cingolani R, Di Fabrizio E. Breaking the diffusion limit with super-hydrophobic delivery of molecules to plasmonic nanofocusing SERS structures. Nature Photonics, 2011, 5, $682-687$.

[130] Zhang Q X, Chen Y X, Guo Z, Liu H L, Wang D P, Huang X J. Bioinspired multifunctional hetero-hierarchical micro/nanostructure tetragonal array with self-cleaning, anticorrosion, and concentrators for the SERS detection. ACS Applied Materials \& Interfaces, 2013, 5, 10633-10642.

[131] Xu B B, Zhang Y L, Zhang W Y, Liu X Q, Wang J N, Zhang X L, Zhang D D, Jiang H B, Zhang R, Sun H B. Silvercoated rose petal: green, facile, low-cost and sustainable fabrication of a SERS substrate with unique superhydrophobicity and high efficiency. Advanced Optical Materials, 2013, 1, 56-60.

[132] Zhao J, Zhang X B, Chen N, Pan Q M. Why superhydrophobicity is crucial for a water-jumping microrobot? Expe- 
rimental and theoretical investigations. ACS Applied Materials \& Interfaces, 2012, 4, 3706-3711.

[133] Zhang X B, Zhao J, Zhu Q, Chen N, Zhang M W, Pan Q M. Bioinspired aquatic microrobot capable of walking on water surface like a water strider. ACS Applied Materials \& Interfaces, 2011, 3, 2630-2636.

[134] Zhang J H, Deng X, Butt H J, Vollmer D. Floating on oil. Langmuir, 2014, 30, 10637-10642.

[135] Liu X L, Gao J, Xue Z X, Chen L, Lin L, Jiang L, Wang S T. Bioinspired oil strider floating at the oil/water interface supported by huge superoleophobic force. ACS Nano, 2012, 6, 5614-5620.

[136] Choi Y, Brugarolas T, Kang S M, Park B J, Kim B S, Lee C $\mathrm{S}$, Lee D. Beauty of lotus is more than skin deep: Highly buoyant superhydrophobic films. ACS Applied Materials \& Interfaces, 2014, 6, 7009-7013.

[137] Lu K. The future of metals. Science, 2010, 328, 319-320.

[138] Liu K S, Jiang L. Metallic surfaces with special wettability. Nanoscale, 2011, 3, 825-838.

[139] Marmur A. The lotus effect: Superhydrophobicity and metastability. Langmuir, 2004, 20, 3517-3519.

[140] Bhushan B, Jung Y C. Natural and biomimetic artificial surfaces for superhydrophobicity, self-cleaning, low adhesion, and drag reduction. Progress in Materials Science, 2011, 56, 1-108.

[141] Koch K, Bhushan B, Ensikat H J, Barthlott W. Self-healing of voids in the wax coating on plant surfaces. Philosophical Transactions of the Royal Society A: Mathematical, Physical and Engineering Sciences, 2009, 367, 1673-1688.

[142] Barthlott W, Schimmel T, Wiersch S, Koch K, Brede M, Barczewski M, Walheim S, Weis A, Kaltenmaier A, Leder A, Bohn H F. The salvinia paradox: Superhydrophobic surfaces with hydrophilic pins for air retention under water. $A d$ vanced Materials, 2010, 22, 2325-2328.

[143] Guo Z G, Liu W M. Biomimic from the superhydrophobic plant leaves in nature: Binary structure and unitary structure. Plant Science, 2007, 172, 1103-1112.

[144] Bixler G D, Bhushan B. Bioinspired rice leaf and butterfly wing surface structures combining shark skin and lotus effects. Soft Matter, 2012, 8, 11271-11284.

[145] Feng L, Zhang Y A, Xi J M, Zhu Y, Wang N, Xia F, Jiang L. Petal effect: A superhydrophobic state with high adhesive force. Langmuir, 2008, 24, 4114-4119.

[146] Karaman M, Çabuk N, Özyurt D, Köysüren Ö. Selfsupporting superhydrophobic thin polymer sheets that mimic the nature's petal effect. Applied Surface Science, 2012, 259, 542-546.
[147] Han Z W, Niu S C, Yang M, Zhang J Q, Yin W, Ren L Q. An ingenious replica templated from the light trapping structure in butterfly wing scales. Nanoscale, 2013, 5, 8500-8506.

[148] Niu S C, Li B, Mu Z Z, Yang M, Zhang J Q, Han Z W, Ren L Q. Excellent structure-based multifunction of Morpho butterfly wings: A review. Journal of Bionic Engineering, 2015, 12, 170-189.

[149] Han Z W, Mu Z Z, Li B, Wang Z, Zhang J Q, Niu S C, Ren L Q. Active antifogging property of monolayer $\mathrm{SiO}_{2}$ film with bioinspired multiscale hierarchical pagoda structures. ACS Nano, 2016, 10, 8591-8602.

[150] Liu C C, Ju J, Zheng Y M, Jiang L. Asymmetric ratchet effect for directional transport of fog drops on static and dynamic butterfly wings. ACS Nano, 2014, 8, 1321-1329.

[151] Min W L, Jiang B, Peng J. Bioinspired self-cleaning antireflection coatings. Advanced Materials, 2010, 20, 3914-3918.

[152] Chattopadhyay S, Huang Y F, Jen Y J, Ganguly A, Chen K $\mathrm{H}$, Chen L C. Anti-reflecting and photonic nanostructures. Materials Science \& Engineering R-Reports, 2010, 69, 1-35.

[153] Autumn K, Liang Y A, Hsieh S T, Zesch W, Chan W P, Kenny T W, Fearing R, Full R J. Adhesive force of a single gecko foot-hair. Nature, 2000, 405, 681-685.

[154] Jin M H, Feng X J, Feng L, Sun T L, Zhai J, Li T J, Jiang L. Superhydrophobic aligned polystyrene nanotube films with high adhesive force. Advanced Materials, 2010, 17, 1977-1981.

[155] Lee H, Lee B, Messersmith P. A reversible wet/dry adhesive inspired by mussels and geckos. Nature, 2007, 448, 338-341.

[156] Gao X F, Jiang L. Biophysics: Water-repellent legs of water striders. Nature, 2004, 432, 36-36.

[157] Wang Q B, Yao X, Liu H. Self-removal of condensed water on the legs of water striders. Proceedings of the National Academy of Sciences of the United States of America, 2015, 112, 9247-9252.

[158] Gao X F, Xin Y, Yao X I, Yao X, Xu L, Zhang K, Zhang J H, Yang B, Jiang L. The dry-style antifogging properties of mosquito compound eyes and artificial analogues prepared by soft lithography. Advanced Materials, 2010, 19, 2213-2217.

[159] Jiang T, Guo Z G, Liu W M. Biomimetic superoleophobic surfaces: Focusing on their fabrication and applications. Journal of Materials Chemistry A, 2015, 3, 1811-1827.

[160] Hensel R, Helbig R, Aland S, Braun H, Voigt A, Neinhuis C, Werner C. Wetting resistance at its topographical limit: The benefit of mushroom and serif T structures. Langmuir, 2013, 


\section{9, 1100-1112.}

[161] Waghmare P, Gunda N, Mitra S. Under-water superoleophobicity of fish scales. Scientific Reports, 2014, 4, 7454.

[162] Manna U, Lynn D. Synthetic surfaces with robust and tunable underwater superoleophobicity. Advanced Functional Materials, 2015, 25, 1672-1681.

[163] Cai Y, Lin L, Xue Z X, Liu M J, Wang S T, Jiang L. Filefishinspired surface design for anisotropic underwater oleophobicity. Advanced Functional Materials, 2014, 24, 809-816.

[164] Xu L P, Peng J T, Liu Y B, Wen Y Q, Zhang X J, Jiang L, Wang S T. Nacre-Inspired design of mechanical stable coating with underwater superoleophobicity. ACS Nano, 2013, 7, 5077-5083.

[165] Xia P, Li G J, Liu Y H. Progress and perspective of studies on biomimetic shark skin drag reduction. Chembioeng Reviews, 2016, 3, 26-40.

[166] Koch K, Bhushan B, Barthlott W. Multifunctional surface structures of plants: An inspiration for biomimetics. Progress in Materials Science, 2009, 54, 137-178.

[167] Bhushan B, Jung Y C, Koch K. Micro-, nano- and hierarchical structures forsuperhydrophobicity, self-cleaning and low adhesion. Philosophical Transactions of the Royal Society A: Mathematical, Physical and Engineering Sciences, 2009, 367, 1631-1672.

[168] Barthlott W, Neinhuis C. Purity of the sacred lotus, or escape from contamination in biological surfaces. Planta, 1997, 202, 1-8.

[169] Helbig R, Nickerl J, Neinhuis C, Werner C. Smart skin patterns protect springtails. PLoS One, 2012, 6, e25105.

[170] Nickerl J, Helbig R, Schulz H J, Werner C, Neinhuis C. Diversity and potential correlations to the function of Collembola cuticle structures. Zoomorphology, 2013, 132, 183-195.

[171] Hensel R, Finn A, Helbig R, Braun H G, Neinhuis C, Fischer W J, Werner C. Biologically inspired omniphobic surfaces by reverse imprintlithography. Advanced Materials, 2014, 26, 2029-2033.

[172] Nickerl J, Tsurkan M, Hensel R, Neinhuis C, Werner C. The multi-layered protective cuticle of Collembola: A chemical analysis. Journal of the Royal Society Interface, 2014, 11, 20140619.

[173] Bixler G D, Bhushan B. Fluid drag reduction and efficient self-cleaning with rice leaf and butterfly wing bioinspired surfaces. Nanoscale, 2013, 5, 7685-7710.

[174] Vinogradova O I, Dubov A L. Superhydrophobic textures for microfluidics. Mendeleev Communications, 2012, 22,
229-236.

[175] Bhushan B. Biomimetics inspired surfaces for drag reduction and oleophobicity/philicity. Beilstein Journal of Nanotechnology, 2011, 2, 66-84.

[176] Ishaq A, Kan C W. A review on development and applications of bio-inspired superhydrophobic textiles. Materials, 2016, 9, 1-34.

[177] Young T. An essay on the cohesion of fluids. Philosophical Transactions of the Royal Society of London, 1805, 95, 65-87.

[178] Wenzel R N. Resistance of solid surfaces to wetting by water. Industrial and Engineering Chemistry, 1936, 28, 988-994.

[179] Wenzel R N. Surface roughness and contact angle. The Journal of Physical Chemistry, 1949, 53, 1466-1467.

[180] Cassie A, Baxter S. Wettability of porous surfaces. Transactions of the Faraday Society, 1944, 40, 546-551.

[181] Patankar N A. Mimicking the lotus effect: Influence of double roughness structures and slender pillars. Langmuir, 2004, 20, 8209-8213.

[182] Ramirez S M, Diaz Y J, Campos R, Stone R L, Haddad T S, Mabry J M. Incompletely condensed fluoroalkyl silsesquioxanes and derivatives: Precursors for low surface energy materials. Journal of the American Chemical Society, 2011, 133, 20084-20087

[183] Tuteja A, Choi W, Ma M L, Mabry J M, Mazzella S A, Rutledge G C, McKinley G H, Cohen R E. Designing superoleophobic surfaces. Science, 2007, 318, 1618-1622.

[184] Tuteja A, Choi W, Mabry J M, McKinley G H, Cohen R E. Robust omniphobic surfaces. Proceedings of the National Academy of Sciences of the United States of America, 2008, 105, 18200-18205.

[185] Marmur A. From hygrophilic to superhygrophobic: Theoretical conditions for making high-contact-angle surfaces from low-contact-angle materials. Langmuir, 2008, 24, 7573-7579.

[186] Nosonovsky M. Multiscale roughness and stability of superhydrophobic biomimetic interfaces. Langmuir, 2007, 23, 3157-3161.

[187] Wong T S, Hoon K S, Tang S K Y, Smythe E J, Hatton B D, Grinthal A, Aizenberg J. Bioinspired self-repairing slippery surfaces with pressure-stable omniphobicity. Nature, 2011, 477, 443-447

[188] Smith J D, Dhiman R, Anand S, Reza-Garduno E, Cohen R E, McKinley G H, Varanasi K K. Droplet mobility on lubricant-impregnated surfaces. Soft Matter, 2013, 9, 1772-1780. 
[189] Liu W, Cai M Y, Luo X, Chen C H, Pan R, Zhang H J, Zhong M L. Wettability transition modes of aluminum surfaces with various micro/nanostructures produced by a femtosecond laser. Journal of Laser Applications, 2019, 31, 022503.

[190] Vorobyev A Y, Guo C L. Multifunctional surfaces produced by femtosecond laser pulses. Journal of Applied Physics, 2015, 117, 033103.

[191] Tao H Y, Song X W, Hao Z Q, Lin J Q. One-step formation of multifunctional nano- and microscale structures on metal surface by femtosecond laser. Chinese Optics Letters, 2015, 13, 061402.

[192] Xing W, Li Z, Yang H U, Li X L, Wang X Y, Li N. Antiicing aluminum alloy surface with multi-level micro-nano textures constructed by picosecond laser. Materials \& Design, 2019, 183, UNSP 108156.

[193] Wang X C, Wang B, Xie H, Zheng H Y, Lam Y C. Picosecond laser micro/nano surface texturing of nickel for superhydrophobicity. Journal of Physics D: Applied Physics, 2018, 51, 115305.

[194] Long J Y, He Z J, Zhou C X, Xie X Z, Cao Z, Zhou P Y, Zhu Y L, Hong W J, Zhou Z S. Hierarchical micro- and nanostructures induced by nanosecond laser on copper for superhydrophobicity, ultralow water adhesion and frost resistance. Materials \& Design, 2018, 155, 185-193.

[195] Yang C J, Zhao Y C, Tian Y L, Wang F J, Liu X P, Jing X B. Fabrication and stability investigation of bio-inspired superhydrophobic surface on nitinol alloy. Colloids \& Surfaces A: Physicochemical \& Engineering Aspects, 2019, 567, 16-26.

[196] Cai Y K, Chang W L, Luo X, Sousa A M L, Lau K H A, Qin Y. Superhydrophobic structures on $316 \mathrm{~L}$ stainless steel surfaces machined by nanosecond pulsed laser. Precision Engineering, 2018, 52, 266-275.

[197] Wang Y H, Cheng W, Zhang D Z, Yu Q Y, Wan Y L, Xu J K, Yu H D. Rapid preparation of high adhesion superhydrophobic surface of T-groove. Materials Research Express, 2019, 6, $0865 \mathrm{~h} 7$.

[198] Dong S L, Wang Z L, Wang Y K, Bai X L, Fu Y Q, Guo B, Tan C L, Zhang J, Hu P A. Roll-to-roll manufacturing of robust superhydrophobic coating on metallic engineering materials. ACS Applied Materials \& Interfaces, 2018, 10, 2174-2184.

[199] Gao D J, Cao J, Guo Z G. Underwater manipulation of oil droplets and bubbles on superhydrophobic surfaces via switchable adhesion. Chemical Communications, 2019, 55, 3394-3397.
[200] Lu Y, Xu W J, Song J L, Liu X, Xing Y J, Sun J. Preparation of superhydrophobic titanium surfaces via electrochemical etching and fluorosilane modification. Applied Surface Science, 2012, 263, 297-301.

[201] Sun J, Zhang F D, Song J L, Wang L, Qu Q S, Lu Y, Parkin I. Electrochemical fabrication of superhydrophobic $\mathrm{Zn}$ surfaces. Applied Surface Science, 2014, 315, 346-352.

[202] Wang B, Guo Z G. Superhydrophobic copper mesh films with rapid oil/water separation properties by electrochemical deposition inspired from butterfly wing. Applied Physics Letters, 2013, 103, 063704.

[203] Gao Y Z, Sun Y W, Guo D M. Facile fabrication of superhydrophobic surfaces with low roughness on Ti-6Al-4V substrates via anodization. Applied Surface Science, 2014, 314, 754-759.

[204] Xiao F, Yuan S J, Liang B, Li G Q, Pehkonen S O, Zhang T J. Superhydrophobic $\mathrm{CuO}$ nanoneedle-covered copper surfaces for anticorrosion. Journal of Materials Chemistry A, 2015, 3, 4374-4388.

[205] Kim J H, Mirzaei A, Kim H W, Kim S S. Facile fabrication of superhydrophobic surfaces from austenitic stainless steel (AISI 304) by chemical etching. Applied Surface Science, 2018, 439, 598-604.

[206] Yang W X, Yuan Y, Liu G Y, Zhang B, Yang R K. The anti-icing/frosting aluminum surface with hydrangea-like micro/nano structure prepared by chemical etching. Materials Letters, 2018, 226, 4-7.

[207] Xiao X Y, Xie W, Ye Z H. Preparation of corrosion-resisting superhydrophobic surface on aluminium substrate. Surface Engineering, 2019, 35, 411-419.

[208] Jiang D Y, Wei Z B, Chen J, Guo X G, Yin L M. Facile one-step chemical deposition process to fabricate superhydrophobic porous $\mathrm{Cu}$ films on $\mathrm{Al}$ alloy surface. Materials Research Innovations, 2016, 22,168-176.

[209] Pi P H, Hou K, Zhou C L, Li G D, Wen X F, Xu S P, Cheng J, Wang S F. Superhydrophobic $\mathrm{Cu}_{2} \mathrm{~S} @ \mathrm{Cu}_{2} \mathrm{O}$ film on copper surface fabricated by a facile chemical bath deposition method and its application in oil-water separation. Applied Surface Science, 2017, 396, 566-573.

[210] Xu X H, Zhang Z Z, Yang J, Zhu X T. Study of the corrosion resistance and loading capacity of superhydrophobic meshes fabricated by spraying method. Colloids and Surfaces A: Physicochemical and Engineering Aspects, 2011, 377, 70-75.

[211] El Dessouky W I, Abbas R, Sadik W A, El Demerdash A G M, Hefnawy A. Improved adhesion of superhydrophobic layer on metal surfaces via one step spraying method. Ara- 
bian Journal of Chemistry, 2017, 10, 368-377.

[212] Shi T, Li X W, Shao J H, Wang H X, Zhang C W, He Y X, He Z Y, Yang D N, Zhong B, Lv Y. One-step machining of hierarchical micro-nano structures on Al-Mg alloy as superamphiphobic substrate for amplified SERS trace detection. Materials Research Express, 2019, 6, 046510.

[213] Liu X, Song J L, Liu J Y, Zhang F D, Sun J, Xu W J. Fabrication of superoleophobic surfaces on $\mathrm{Zn}$ substrates by electrochemical etching and perfluorooctanoic acid modification. Micro \& Nano Letters, 2016, 11, 109-113.

[214] Wang T Y Y, Cai J Y, Wu Y W, Hang T, Hu A M, Ling H Q, Li M. Applicable superamphiphobic $\mathrm{Ni} / \mathrm{Cu}$ surface with high liquid repellency enabled by the electrochemicaldeposited dual-scale structure. ACS Applied Materials \& Interfaces, 2019, 11, 11106-11111.

[215] Sun Y W, Wang L L, Gao Y Z, Guo D M. Preparation of stable superamphiphobic surfaces on Ti-6Al-4V substrates by one-step anodization. Applied Surface Science, 2015, 324, 825-830.

[216] Liu Y, Li S Y, Wang Y M, Wang H Y, Gao K, Han Z W, Ren L Q. Superhydrophobic and superoleophobic surface by electrodeposition on magnesium alloy substrate: Wettability and corrosion inhibition. Journal of Colloid and Interface Science, 2016, 478, 164-171.

[217] Peng S, Bhushan B. Mechanically durable superoleophobic aluminum surfaces with microstep and nanoreticula hierarchical structure for self-cleaning and anti-smudge properties. Journal of Colloid and Interface Science, 2016, 461, 273-284.

[218] Shi T, Kong J Y, Wang X D, Li X W. Preparation of multifunctional $\mathrm{Al}-\mathrm{Mg}$ alloy surface with hierarchical micro/nanostructures by selective chemical etching processes. Applied Surface Science, 2016, 389, 335-343.

[219] Huang L, Song J L, Lu Y, Chen F Z, Liu X, Jin Z J, Zhao D Y, Carmalt C J, Parkin I P. Superoleophobic surfaces on stainless steel substrates obtained by chemical bath deposition. Micro \& Nano Letters, 2017, 12, 76-81.

[220] Motlagh N V, Sargolzaei J, Shahtahmassebi N. Superliquid-repellent coating on the carbon steel surface. Surface \& Coatings Technology, 2013, 235, 241-249.

[221] Zhang J Z, Yong J L, Yang Q, Chen F, Hou X. Femtosecond laser-induced underwater superoleophobic surfaces with reversible pH-responsive wettability. Langmuir, 2019, 35, 3295-3301.

[222] Yin K, Song Y X, Dong R, Wang C, Duan J A. Underwater superoleophobicity, anti-oil and ultra-broadband enhanced absorption of metallic surfaces produced by a femtosecond laser inspired by fish and chameleons. Scientific Reports, 2016, 6, 36557.

[223] Pi P H, Hou K, Zhou C L, Wen X F, Xu S P, Cheng J, Wang $\mathrm{S}$ F. A novel superhydrophilic-underwater superoleophobic $\mathrm{Cu}_{2} \mathrm{~S}$ coated copper mesh for efficient oil-water separation. Materials Letters, 2016, 182, 68-71.

[224]Wang B, Guo Z G. pH-responsive bidirectional oil-water separation material. Chemical Communications, 2013, 49, 9416-9418.

[225] Huang J Y, Lai Y K, Wang L N, Li S H, Ge M Z, Zhang K Q, Fuchs H, Chi L F. Controllable wettability and adhesion on bioinspired multifunctional $\mathrm{TiO}_{2}$ nanostructure surfaces for liquid manipulation. Journal of Materials Chemistry A, 2014, 2, 18531-18538.

[226] Zhou C L, Cheng J, Hou K, Zhu Z T, Zheng Y F. Preparation of $\mathrm{CuWO}_{4} @ \mathrm{Cu}_{2} \mathrm{O}$ film on copper mesh by anodization for oil/water separation and aqueous pollutant degradation. Chemical Engineering Journal, 2016, 307, 803-811.

[227] Cho H, Lee J, Lee S H, Wang W. Durable superhydrophilic/phobic surfaces based on green patina with corrosion resistance. Physical Chemistry Chemical Physics, 2015, 17, 6786-6793.

[228] Tie L, Li J, Guo Z G, Liang Y M, Liu W M. Controllable preparation of multiple superantiwetting surfaces: From dual to quadruple superlyophobicity. Chemical Engineering Journal, 2019, 369, 463-469

[229] Wang J T, Wu J L, Han F L. Eco-friendly and scratchresistant hybrid coating on mesh for gravity-driven oil/water separation. Journal of Cleaner Production, 2019, 241, UNSP 118369.

[230] Doll K, Yang I, Fadeeva E, Kommerein N, Szafranski S P, Wieden G B D, Greuling A, Winkel A, Chichkov B N, Stumpp N S, Stiesch M. Liquid-infused structured titanium surfaces: Antiadhesive mechanism to repel streptococcus oralis biofilms. ACS Applied Materials \& Interfaces, 2019, 11, 23026-23038.

[231] Zouaghi S, Six T, Bellayer S, Moradi S, Hatzikiriakos S G, Dargent T, Thomy V, Coffinier Y, Andre C, Delaplace G, Jimenez M. Antifouling biomimetic liquid-infused stainless steel: Application to dairy industrial processing. ACS Applied Materials \& Interfaces, 2017, 9, 26565-26573.

[232] Ma Q, Wang W, Dong G N. Facile fabrication of biomimetic liquid-infused slippery surface on carbon steel and its self-cleaning, anti-corrosion, anti-frosting and tribological properties. Colloids and Surfaces A: Physicochemical and Engineering Aspects, 2019, 577, 17-26.

[233] Luo H, Yin S H, Huang S, Chen F J, Tang Q C, Li X J. 
Fabrication of slippery $\mathrm{Zn}$ surface with improved waterimpellent, condensation and anti-icing properties. Applied Surface Science, 2019, 470, 1139-1147.

[234] Ouyang Y B, Zhao J, Qiu R, Hu S G, Chen M, Wang P. Liquid-infused superhydrophobic dendritic silver matrix: A bio-inspired strategy to prohibit biofouling on titanium. Surface \& Coatings Technology, 2019, 367, 148-155.

[235] Qiu Z H, Qiu R, Xiao Y M, Zheng J Y, Lin C G. Slippery liquid-infused porous surface fabricated on $\mathrm{CuZn}$ : A barrier to abioticseawater corrosion and microbiologically induced corrosion. Applied Surface Science, 2018, 457, 468-476.

[236] Kietzig A M, Hatzikiriakos S G, Englezos P. Patterned superhydrophobic metallic surfaces. Langmuir, 2009, 25, 4821-4827.

[237] Long J Y, Zhong M L, Zhang H J, Fan P X. Superhydrophilicity to superhydrophobicity transition of picosecond laser microstructured aluminum in ambient air. Journal of Colloid and Interface Science, 2015, 441, 1-9.

[238] Lian Z X, Xu J K, Yu Z J, Yu P, Yu H D. A simple two-step approach for the fabrication of bio-inspired superhydrophobic and anisotropic wetting surfaces having corrosion resistance. Journal of Alloys and Compounds, 2019, 793, 326-335.

[239] Bae W G, Song K Y, Rahmawan Y, Chu C N, Kim D, Chung D K, Suh K Y. One-step process for superhydrophobic metallic surfaces by wire electrical discharge machining. ACS Applied Materials \& Interfaces, 2012, 4, 3685-3691.

[240] Wan Y L, Lou J, Yu Z J, Li X Z, Yu H D. Single-step fabrication of bionic-superhydrophobic surface using reciprocating-type high-speed wire cut electrical discharge machining. Chinese Science Bulletin, 2014, 59, 3691-3695.

[241] Liu Y, Xue J Z, Luo D, Wang H Y, Gong X, Han Z W, Ren L Q. One-step fabrication of biomimetic superhydrophobic surface by electrodeposition on magnesium alloy and its corrosion inhibition. Journal of Colloid and Interface Science, 2017, 491, 313-320.

[242] Peng S, Tian D, Yang X J, Deng W L. Highly efficient and large-scale fabrication ofsuperhydrophobic alumina surface with strong stability based on self-congregated alumina nanowires. ACS Applied Materials \& Interfaces, 2014, 6, 4831-4841.

[243] Qian B T, Shen Z Q. Fabrication of superhydrophobic surfaces by dislocation-selective chemical etching on aluminum, copper, and zinc substrates. Langmuir, 2005, 21, 9007-9009.

[244] Choi H J, Shin J H, Choo S, Ryu S W, Kim Y D, Lee H. Fabrication of superhydrophobic and oleophobic Al surfaces by chemical etching and surface fluorination. Thin Solid Films, 2015, 585, 76-80.

[245] Song J L, Xu W J, Liu X, Wei Z F, Lu Y. Fabrication of superhydrophobic $\mathrm{Cu}$ surfaces on $\mathrm{Al}$ substrates via a facile chemical deposition process. Materials Letters, 2012, 87, 43-46.

[246] Qi X, Song W, Mao Z, Gao W R, Cong Q. Fabrication of a bionic needle with both super-hydrophobic and antibacterial properties. Journal of Bionic Engineering, 2013, 10, 377-382.

[247] Li J, Wu R N, Jing Z J, Yan L, Zha F, Lei Z Q. One-step spray-coating process for the fabrication of colorful superhydrophobic coatings with excellent corrosion resistance. Langmuir, 2015, 31, 10702-10707.

[248] Guo D Y, Hou K, Xu S P, Lin Y G, Li L, Wen X F, Pi P H. Superhydrophobic-superoleophilic stainless steel meshes by spray-coating of a POSS hybrid acrylic polymer for oil-water separation. Journal of Materials Science, 2018, 53, 6403-6413.

[249] Weisensee P B, Torrealba E J, Raleigh M, Jacobi A M, King W P. Hydrophobic and oleophobic re-entrant steel microstructures fabricated using micro electrical discharge machining. Journal of Micromechanics and Microengineering, 2014, 24, 095020.

[250] Yu H D, Lian Z X, Wan Y L, Weng Z K, Xu J K, Yu Z J. Fabrication of durable superamphiphobic aluminum alloy surfaces with anisotropic sliding by HS-WEDM and solution immersion processes. Surface and Coatings Technology, 2015, 275, 112-119.

[251] Lu Y, Song J L, Liu X, Xu W J, Xing Y J, Wei Z F. Preparation of superoleophobic and superhydrophobic titanium surfaces via an environmentally friendly electrochemical etching method. ACS Sustainable Chemistry \& Engineering, 2013, 1, 102-109.

[252] Yang J, Zhang Z Z, Xu X H, Men X H, Zhu X T, Zhou X Y. Superoleophobic textured aluminum surfaces. New Journal of Chemistry, 2011, 35, 2422-2426.

[253] Ji S, Ramadhianti P A, Nguyen T B, Kim W D, Lim H. Simple fabrication approach for superhydrophobic and superoleophobic Al surface. Microelectronic Engineering, 2013, 111, 404-408.

[254] Zhu X T, Zhang Z Z, Xu X H, Men X H, Yang J, Zhou X Y, Xue Q J. Facile fabrication of a superamphiphobic surface on the copper substrate. Journal of Colloid and Interface Science, 2012, 367, 443-449.

[255] Ou J F, Hu W H, Liu S, Xue M S, Wang F J, Li W. Superoleophobic textured copper surfaces fabricated by chemical 
etching/oxidation and surface fluorination. ACS Applied Materials \& Interfaces, 2013, 5, 10035-10041.

[256] Ge B, Zhang Z Z, Men X H, Zhu X T, Zhou X Y. Sprayed superamphiphobic coatings on copper substrate with enhanced corrosive resistance. Applied Surface Science, 2014, 293, 271-274.

[257] Tang Y C, Yang J, Yin L T, Chen B B, Tang H, Liu C, Li C S. Fabrication of superhydrophobic polyurethane/ $\mathrm{MoS}_{2}$ nanocomposite coatings with wear-resistance. Colloids and Surfaces A: Physicochemical and Engineering Aspects, 2014, 459, 261-266.

[258] Kota A K, Li Y X, Mabry J M, Tuteja A. Hierarchically structured superoleophobic surfaces with ultralow contact angle hysteresis. Advanced Materials, 2012, 24, 5838-5843.

[259] Pan S J, Kota A K, Mabry J M, Tuteja A. Superomniphobic surfaces for effective chemical shielding. Journal of the American Chemical Society, 2013, 135, 578-581.

[260] Yong J L, Chen F, Yang Q, Farooq U, Hou X. Photoinduced switchable underwater superoleophobicitysuperoleophilicity on laser modified titanium surfaces. Journal of Materials Chemistry A, 2015, 3, 10703-10709.

[261] Ye S, Cao Q, Wang Q, Wang T Y, Peng Q. A highly efficient, stable, durable, and recyclable filter fabricated by femtosecond laser drilling of a titanium foil for oil-water separation. Scientific Reports, 2016, 6, 37591.

[262] Yu H D, Lian Z X, Xu J K, Wan Y L, Wang Z B, Li Y Q, Weng Z K. Mechanically durable underwater superoleophobic surfaces based on hydrophilic bulk metals for oil/water separation. Applied Surface Science, 2018, 437, 400-409.

[263] Lian Z X, Xu J K, Wang Z B, Wang Z C, Weng Z K, Yu H D. Fabrication and applications of two- and three-dimensional curved surfaces with robust underwater superoleophobic properties. Journal of Materials Science, 2017, 52, $1123-1136$.

[264] Lian Z X, Xu J K, Wan Y L, Li Y Q, Yu Z J, Liu Q M, Yu H D. Tribological properties of fish scale inspired underwater superoleophobic hierarchical structure in aqueous environment. Materials Research Express, 2017, 4, 106504.

[265] Wang L L, Sun Y W, Gao Y Z, Guo D M. Preparation of durable underwater superoleophobic Ti6Al4V surfaces by electrochemical etching. Surface Engineering, 2016, 32, 85-94.

[266] Hou Y Y, Li R Q, Liang J. Superhydrophilic nickel-coated meshes with controllable pore size prepared by electrodeposition from deep eutectic solvent for efficient oil/water separation. Separation and Purification Technology, 2018,
192, 21-29.

[267] Ma X L, Luo H, Ma J, Wang P W, Xu X L, Jing G Y. A facile approach for fabrication of underwater superoleophobic alloy. Applied Physics A, 2013, 113, 693-702.

[268] Nishimoto S, Ota M, Kameshima Y, Miyake M. Underwater superoleophobicity of a robust rough titanium dioxide surface formed on titanium substrate by acid treatment. Colloids and Surfaces A: Physicochemical and Engineering Aspects, 2015, 464, 33-40.

[269] Li J H, Cheng H M, Chan C Y, Ng P F, Chen L, Fei B, Xin J H. Superhydrophilic and underwater superoleophobic mesh coating for efficient oil-water separation. RSC Advances, 2015, 5, 51537-51541.

[270]Li J, Yan L, Li H Y, Li W J, Zha F, Lei Z Q. Underwater superoleophobic palygorskite coated mesh for the efficient oil/water separation. Journal of Materials Chemistry A, 2015, 3, 14696-14702.

[271] Gunatilake U B, Bandara J. Efficient removal of oil from oil contaminated water by superhydrophilic and underwater superoleophobic nano/micro structured $\mathrm{TiO}_{2}$ nanofibers coated mesh. Chemosphere, 2017, 171, 134-141.

[272] Doll K, Fadeeva E, Schaeske J, Ehmke T, Winkel A, Heisterkamp A, Chichkov B N, Stiesch M, Stumpp N S. Development of laser-structured liquid-infused titanium with strong biofilm-repellent properties. ACS Applied Materials \& Interfaces, 2017, 9, 9359-9368.

[273] Wang P, Zhang D, Lu Z, Sun S M. Fabrication of slippery lubricant-infused porous surface for inhibition of microbially influenced corrosion. ACS Applied Materials \& Interfaces, 2016, 8, 1120-1127.

[274] Wang N, Xiong D S, Pan S, Deng Y L, Shi Y. Fabrication of superhydrophobic and lyophobic slippery surface on steel substrate. Applied Surface Science, 2016, 387, 1219-1224.

[275] Yang J, Song H J, Ji H Y, Chen B B. Slippery lubricantinfused textured aluminum surfaces. Journal of Adhesion Science and Technology, 2014, 28, 1949-1957.

[276] Gao X Y, Guo Z G. Mechanical stability, corrosion resistance of superhydrophobic steel and repairable durability of its slippery surface. Journal of Colloid and Interface Science, 2017, 512, 239-248.

[277] Lu S X, Chen Y L, Xu W G, Liu W. Controlled growth of superhydrophobic films by sol-gel method on aluminum substrate. Applied Surface Science, 2010, 256, 6072-6075.

[278] Hou K, Zeng Y C, Zhou C L, Chen J H, Wen X F, Xu S P, Cheng J, Lin Y G, Pi P H. Durable underwater superoleophobic PDDA/halloysite nanotubes decorated stainless steel mesh for efficient oil-water separation. Applied Surface 
Science, 2017, 416, 344-352.

[279] Jo S, Kim Y. Superhydrophilic-underwater superoleophobic $\mathrm{TiO}_{2}$-coated mesh for separation of oil from oily seawater/wastewater. Korean Journal of Chemical Engineering, 2016, 33, 3203-3206.

[280] Latthe S S, Sudhagar P, Devadoss A, Kumar A M, Liu S H, Terashima C, Nakata K, Fujishima A. A mechanically bendable superhydrophobic steel surface with self-cleaning and corrosion-resistant properties. Journal of Materials Chemistry A, 2015, 3, 14263-14271.

[281] Liu H L, Zhang P C, Liu M J, Wang S T, Jiang L. Organogelbased thin films for self-cleaning on various surfaces. $A d$ vanced Materials, 2013, 25, 4477-4481.

[282] Boinovich L B, Emelyanenko A M, Ivanov V K, Pashinin A S. Durable icephobic coating for stainless steel. ACS Applied Materials \& Interfaces, 2013, 5, 2549-2554.

[283] Zang D M, Zhu R W, Zhang W, Yu X Q, Lin L, Guo X L, Liu M J, Jiang L. Corrosion-resistant superhydrophobic coatings on $\mathrm{Mg}$ alloy surfaces inspired by lotus seedpod. Advanced Functional Materials, 2017, 27, 1605446.

[284] Wang P, Lu Z, Zhang D. Slippery liquid-infused porous surfaces fabricated on aluminum as a barrier to corrosion induced by sulfate reducing bacteria. Corrosion Science,
2015, 93, 159-166.

[285] Tuo Y J, Zhang H F, Chen W P, Liu X W. Corrosion protection application of slippery liquid-infused porous surface based on aluminum foil. Applied Surface Science, 2017, 423, 365-374.

[286] Choi C H, Kim C J. Large slip of aqueous liquid flow over a nanoengineered superhydrophobic surface. Physical Review Letters, 2006, 96, 066001.

[287] Gogte S, Vorobieff P, Truesdell R, Mammoli A. Effective slip on textured superhydrophobic surfaces. Physics of Fluids, 2005, 17, 051701.

[288] Rothstein J P. Slip on superhydrophobic surfaces. Fluid Mechanics, 2010, 42, 89-109.

[289] Voronov R S, Papavassiliou D V, Lee L L. Review of fluid slip over superhydrophobic surfaces and its dependence on the contact angle. Industrial and Engineering Chemistry Research, 2008, 47, 2455-2477.

[290] Truesdell R, Mammoli A, Vorobieff P, Van Swol F, Brinker C J. Drag reduction on a patterned superhydrophobic surface. Physical Review Letters, 2006, 97, 044504.

[291] Weng R, Zhang H F, Liu X W. The nanostructured superoleophobic liquid-floated rotor gyroscope. Microelectronic Engineering, 2014, 119, 183-187. 